\title{
ANÁLISIS DE LA EXCLUSIÓN A PARTIR DE LA DELINCUENCIA JUVENIL EN LA CIUDAD DE VALENCIA. EL TERRITORIO COMO BASE PARA LA INTERVENCIÓN ${ }^{1}$
}

\author{
María Dolores Pitarch Garrido \\ Francesc Xavier Uceda i Maza \\ Instituto Interuniversitario de Desarrollo Local. Universitat de València \\ maria.pitarch@uv.es ; francesc.uceda@uv.es
}

\section{RESUMEN}

La inseguridad, en la llamada sociedad del riesgo, se traduce en reivindicación de seguridad frente a la delincuencia. La ambivalencia y la pluralidad de la sociedad postmoderna se debate entre la concepción de estructuras de intervención rígidas, penalizadoras y centradas en el individuo como responsable único de su acción o, por el contrario, en articular un modelo donde la sociedad se apodere de sus conflictos y haga, de la responsabilidad, un bien social del que ocuparse. De tal manera que la responsabilidad no es individual, sino grupal y colectiva siendo clave para ello el territorio.

En este artículo se parte de este último postulado, el territorio donde se desarrolla la trayectoria delictiva, el escenario social (equipamiento público, escuela, programas y talleres para jóvenes, servicios sociales, etc.), es clave para el itinerario de intervención socio-educativa, pues es donde las políticas de proximidad favorecen la convivencia y la integración de las personas.

Fecha de recepción: julio 2013.

Fecha de aceptación: julio 2014.

1 El presente artículo se ha elaborado en el marco del proyecto de investigación financiado por el Plan Nacional de I+D+I del Ministerio de Economía y Competitividad titulado: Sostenibilidad ambiental y social en espacios metropolitanos. El caso del Área Metropolitana de València (CSO2010-20481). Una parte del mismo se presentó en forma de comunicación en el XIII Congreso de la Población Española, celebrado en Santander entre los días 12 y 14 de septiembre de 2012 . 
Sostenemos que la forma más eficaz y eficiente de aumentar la seguridad es promoviendo un territorio estructurado y cohesionado, implementado políticas sociales de proximidad. En este sentido se presenta la situación de los adolescentes en conflicto con la ley en la ciudad de València.

Palabras clave: Vulnerabilidad social, espacios de exclusión, delincuencia, adolescentes, Valencia.

\begin{abstract}
Insecurity, in this society of risk, claim translates into safety from crime. The ambivalence and plurality of postmodern society is torn between the conception of rigid structures for intervention, penalizing and focused on the individual as solely responsible for their action or otherwise articulating a model where society takes possession of their conflicts and the responsibility to deal with as a social good. So that the responsibility is not individual but collective and in that, one of the key aspects is the territory.

This article follows of the latter postulate. The territory, where criminal career develops and where the social scene is (public facilities, schools, programs and workshops for youth, social services, etc..), is key to the socio-educational intervention as it is where community policies promote coexistence and integration of people.

We argue that the most effective and efficient way to increase safety is promoting a structured and cohesive territory, where local social policies are implemented. In this article we present the situation of teenagers in conflict with the law in the city of Valencia.
\end{abstract}

Keywords: Social vulnerability, exclusion areas, crime, teenagers, Valencia.

\title{
I. INTRODUCCIÓN
}

Las ciudades son pequeños (o grandes) universos en los que se concentran los procesos humanos más complejos y más simples. Son laboratorios para el estudio de las interrelaciones entre diferentes variables cambiantes en el tiempo pero a la vez recurrentes y estables. Desde el siglo XIX, pero con mayor énfasis desde los años 50 del siglo XX, el estudio de los espacios de exclusión por parte de los científicos sociales ha sido una constante. La capacidad del territorio, o los barrios urbanos, para generar por sí mismos identidad y pertenencia, así como exclusión y marginación de su población ha sido más que demostrada y no supone hoy contestación ni científica ni social.

Las dinámicas económicas del mundo actual están generando una precarización del empleo y una brecha social cada vez mayor, que tiene un claro reflejo en el interior de las ciudades. Sin embargo, los estudios de Geografía sobre la delimitación de barrios según sus características sociales, tanto si son percibidas por la población como si son resultado de las estadísticas oficiales, no son tan abundantes como parecería, habiendo dejado esta tarea a otras disciplinas, como la Sociología, que han pasado de puntillas sobre la necesaria reflexión acerca del tema de la desigualdad y exclusión social desde y para el territorio. 
Es, pues, necesario, aproximarnos al problema de la exclusión social desde la geografía, ya que los territorios, o en el caso de las ciudades, los barrios percibidos, tienen la capacidad de generar una imagen colectiva sobre sus habitantes dando lugar, en algunos casos, a una dura estigmatización de los mismos, en particular en aquellos barrios cuyos habitantes han quedado, a lo largo de los años de configuración de los mismos, al margen del desarrollo económico, político y cultural de la ciudad. En tales casos, el estigma se constituye en la base de su propia identidad, retroalimentando el proceso y limitando las posibilidades de mejora social (Subirats, 2005).

Subdisciplinas tan especializadas como la Geografía del Delito, la Geografía de la Delincuencia o la Geografía del Crimen, han abordado el análisis de la violencia urbana desde el punto de vista territorial (Herbert, 1982, Lahosa, 2002, Hernando, 2006, Fraile y Bonastra, 2011), básicamente buscando la lógica locacional de la comisión del delito, con el fin, en muchas ocasiones, de ser útil para la acción policial o de los jueces mediante la cartografía de los mismos.

Cierto es que la seguridad es una de las principales preocupaciones de los ciudadanos y ya por sí sola justificaría el esfuerzo por construir modelos interpretativos de las dinámicas territoriales de los factores que originan la sensación de inseguridad. Sin embargo, no es el enfoque que queremos dar a nuestra investigación. En el presente artículo partimos de la idea de que las condiciones y prácticas sociales, así como las características del hábitat, influyen en la inseguridad del barrio, pero la influencia del entorno en el que se encuentra una persona puede también modelar su permeabilidad a la comisión de delitos. La exclusión social conlleva resultados negativos para las personas, en particular los jóvenes, que la sufren y puede acabar en trayectorias delictivas diversas. La exclusión social, que supone también exclusión del consumo, del ocio, etc., genera y alimenta un sentimiento de inseguridad que origina y fomenta la segregación y fragmentación de los barrios o territorios en los que se produce. Así, como señalan Cabrales y Canosa (2003), «la búsqueda de seguridad acentúa el repliegue a los espacios privados, como si la sociedad fragilizada no soportase ya la vulnerabilidad de los espacios públicos asociados a la pobreza y a la delincuencia.» (p. 557). Esos espacios, en los que residen los jóvenes en conflicto con la ley serán la base territorial de nuestro análisis.

Por otra parte, la inseguridad es consecuencia y causa del aislamiento y la descohesión social de ciertos barrios, que, a su vez coinciden, con la ausencia de recursos y equipamientos públicos (Arias, 2000). La distribución espacial de los servicios públicos es una variable que explica, entre otras, la exclusión social (Allard, 2004). En el caso que nos ocupa, será de gran importancia conocer la ubicación y la accesibilidad real de los centros de reeducación (medio cerrado) y el equipo de medidas judiciales (medio abierto) para adolescentes en la ciudad de Valencia. La sostenibilidad territorial y social busca el equilibrio, es decir, la equidad en el acceso a los servicios e infraestructuras que son un derecho de todos los ciudadanos. Este equilibrio no es fácil de conseguir ni de medir. Una forma de hacerlo es a través de la accesibilidad.

El territorio de estudio que se presenta es la ciudad de Valencia, y partiendo de la conexión entre territorio, vulnerabilidad y adolescentes en conflicto con la ley (en adelante ACL), nuestra investigación se basa en las siguientes hipótesis: a) Existe una relación entre la vulnerabilidad social en adolescentes, territorios y actividad delictiva; b) El territorio 
vulnerable es clave en el desarrollo de la actividad delictiva y en el tipo de trayectoria en el sentido de a más exclusión social más consolidación de la trayectoria delictiva; c) La ubicación del equipo de medidas judiciales y de los centros no permite una accesibilidad óptima para trabajar el acompañamiento social y educativo que precisa una medida judicial y d) La distancia de los centros de reeducación, comporta que medidas de semiabierto o abierto acaben transformándose en internamiento cerrado, es decir comportan mayor aislamiento del territorio y comunidad de referencia para la inserción.

El territorio ha de ser clave en el proceso de intervención social por parte de los poderes públicos. El caso de la ciudad de Valencia resulta paradigmático y la metodología utilizada, así como el enfoque multidisciplinar, puede servir de base a otros estudios posteriores.

\section{LA GEOGRAFÍA SOCIAL COMO MARCO TEÓRICO PARA LOS ESTUDIOS DE DESIGUALDAD}

\section{II.1. La ciudad: territorio y vulnerabilidad social}

La Geografía Social es una subdisciplina de la Geografía que se centra en la forma en que los grupos sociales interaccionan entre sí y con su entorno. A lo largo del tiempo diferentes filosofías y teorías han influido en la Geografía Humana, y con ella en la Geografía Social, que, al consolidarse en el último cuarto del siglo XX, ha incorporado como temas preferentes la pobreza y la desigualdad asociadas al entorno o al territorio en el que las personas desarrollan su vida. El dinamismo socioespacial es entendido como un proceso variable y cambiante, relacionado con cuestiones como el poder, la identidad y la política. Estos aspectos, que producen relaciones sociales desiguales y tienen reflejo en el territorio, son susceptibles de cambio y pueden ser estudiados y cartografiados a diferentes escalas, desde el barrio hasta territorios supranacionales. Sin embargo, es la ciudad, el espacio en el que la Geografía Social ha desarrollado buena parte de su desarrollo científico. Las características materiales de la ciudad y sus barrios, así como las opiniones, sentimientos y expresiones sociales de sus habitantes están entre los temas de estudio de esta subdisciplina que ha recogido influencias de la Geografía Urbana, la Geografía Cultural y de otras disciplinas, en particular de la Sociología.

La vulnerabilidad social ha sido una de las preocupaciones más profundas de la Geografía Social, vinculada a temas como la desigualdad, la identidad social, la provisión de servicios públicos y la pobreza (Pain, 2003).

En la sociedad postmoderna, los riesgos se han ampliado y diversificado haciéndonos más vulnerables en extensión e intensidad, pues las dinámicas económicas asociadas a la globalización suponen un cambio en la evolución de la relación entre capital y trabajo que agudiza la precarización del empleo y la debilitación de los sistemas de protección públicos (Castells, 1995). En este sentido, Castel (1997) señala que la sociedad actual se caracteriza por una cada vez mayor zona de vulnerabilidad, antesala de la exclusión. Bourdieu (1999) caracteriza la vulnerabilidad como un estado permanente de precarité, inseguridad de nivel social, incertidumbre del futuro y sentimiento de no controlar el presente que se combina con una incapacidad de construir proyecciones futuras y actuar coherentemente. Son muchos y diversos los colectivos en situaciones de especial vulnerabilidad, y la adolescencia es uno de los grupos más invisibles y con más dificultades. 
La Geografía Social ha obtenido gran parte de su desarrollo teórico de la escuela de sociólogos de Chicago, en particular de Park, Burgess y Wirth, aunque no sólo. Estos autores observaron que las ciudades norteamericanas de la década de 1920 presentaban ciertas regularidades en su estructura espacial que, en cierta forma, era mantenida por una estructura sociocultural que Park denominaba «el orden moral». Fue la producción de conocimientos sistemáticos sobre Chicago el punto de inflexión en el que la ciudad dejó de verse como un fenómeno únicamente territorial a ser considerada como un organismo social. En este contexto se dieron las primeras investigaciones sobre la delincuencia que se centraron en el medio propio en el que los individuos actúan, en los factores de la organización y el proceso social que los individuos debían llevar a cabo para adaptarse al ambiente. Los investigadores se concentraron principalmente en el ajuste en barrios de clase baja, viviendas deterioradas, alta densidad de población, áreas con una población heterogénea y los consiguientes conflictos culturales, efectos de la urbanización, desempleo, pobreza, rupturas familiares, etc. Todo ello en un contexto de fuerte industrialización y enorme flujo de inmigrantes (Park y Burguess, 1984 [1925], Wirth, 1927).

A partir de la década de los años 50 del siglo XX, se renuevan los estudios sobre la ciudad, particularmente en Francia, donde el Estado promovió la investigación sobre lo que denominó «revolución urbana». Durante estos años, se aplicó el análisis marxista al fenómeno urbano con el objetivo de explicar las desigualdades territoriales y los conflictos que se derivan de las mismas. H. Lefebvre es su máximo exponente y a él se debe la idea de que el espacio urbano es el lugar de la acción y la posibilidad social de comprometerse en la acción. Esta idea será recogida por la Geografía Social e incluso redescubierta en estudios recientes que reivindican la acción política como consecuencia del análisis social (Martin, 2001, Pain, 2003).

En los 60, la denominada Nueva Sociología Urbana introduce nuevas teorías para abordar el tema de la segregación urbana. Sin embargo, como señala Harvey (1976), Engels ya había indicado, 80 años antes, en su obra «La situación de la clase obrera en Inglaterra en 1844» que existe un mecanismo de mercado que genera una división de la ciudad en espacios excluyentes según, principalmente, el valor del suelo. En definitiva, desde mediados del siglo XIX diferentes aportaciones desde distintos ámbitos han enriquecido a la Geografía y han puesto los temas sociales entre los de mayor relevancia, sobre todo en el ámbito urbano. Harvey (1977), uno de los principales autores de esta etapa, desarrolla la idea de la relación entre la especialización del suelo y los procesos de segregación urbana dentro de la lógica capitalista, como base para explicar la desigualdad social. La relación entre espacio urbano y segregación social se hace cada vez más evidente.

En Estados Unidos, la actual estructura urbana ha producido según Soja (1996), un paisaje de encuentros violentos, fronteras inestables y espacios de desesperación. Habla de una geografía de fortificación o carcelaria, de continua vigilancia y sistema de control espacial y social. En el marco del capitalismo neoliberal no hay espacio para la protesta ni para la delincuencia, sino para la represión, lo cual da lugar a nuevos conflictos urbanos.

En Europa, el incremento del riesgo de vulnerabilidad así como la emergencia de marginalidad urbana no han supuesto la guetización de determinados barrios, sino la diferenciación social y concentración de desventaja social en determinadas partes de la ciudad, con alto predominio en los barrios periféricos (Paugam, 2007 y Wacquant, 2008). La evi- 
dencia de procesos de segregación urbana y residencial sumados a indicios de segregación escolar, agudizan las divisiones y las tensiones étnico-raciales que tienen lugar principalmente en barrios desfavorecidos. Los problemas de marginalidad urbana son un tema cada vez más presente en las agendas políticas y sociales ya que amenazan con ser problemas crónicos y con cuestionar los modos tradicionales de ciudadanía (Wacquant, 2007).

Coincidiendo con este contexto de intensificación de las desigualdades socio-espaciales, y por tanto de un aumento del número de áreas urbanas desfavorecidas (Atkinson y Kintrea, 2001), el debate sobre los efectos del barrio ha suscitado un interés que va in crescendo. Los trabajos empíricos de Brooks-Gunn et al. (1993) señalan que vivir en un determinado barrio impacta sobre el comportamiento social, la calidad de vida y las oportunidades de futuro de quienes viven en él, haciendo especial hincapié en la influencia negativa, especialmente donde existen importantes deficiencias en equipamientos y servicios sociales dirigidos a la ciudadanía (Wilson, 1987; Jencks y Mayer, 1990; Musterd et al., 2006). Más concretamente y en un ámbito más cercano, Porcel et al. (2011) estudian en qué medida el área residencial es un factor que condiciona la distribución de oportunidades entre la población joven de la Región Metropolitana de Barcelona. El territorio se configura, pues, como un elemento fundamental para explicar la exclusión social. El análisis del mismo es complejo, como el propio espacio, debido a la multitud de interrelaciones existentes, sinergias y ralentizaciones, por lo que el enfoque interdisciplinar se configura como el más adecuado. Pero si el territorio explica parte de la exclusión social, también es el escenario ideal para la inclusión social, fundamentalmente de población juvenil.

\section{II.2.El territorio, exclusión e inclusión social: La proximidad como estrategia para la interven- ción social}

El territorio introduce desigualdades. Sus características físicas y, sobre todo, humanas (redes de transporte, equipamientos, usos del suelo, etc.) hacen casi imposible la igualdad de oportunidades real. El lugar de residencia de cada persona y la forma en que experimenta o vive su realidad (determinada por su entorno), contribuye, junto con otros factores, a explicar las diferencias sociales y las divergentes trayectorias de vida de muchas personas, en particular jóvenes.

El proceso de globalización, agudizado desde finales del siglo pasado, ha supuesto paradójicamente un fortalecimiento de lo local como respuesta de la ciudadanía ante el sentimiento de pérdida de control de sus propias vidas: lo local frente a lo global (Castells, 1995), a pesar de que, en realidad, ambos términos se complementan y refuerzan, pues existe un sentido global de lo local (Massey, 2004), y viceversa. Sin embargo, lo local es el espacio de los lugares en el que se construye y practica la experiencia, el espacio de la vida cotidiana de la gran mayoría de las personas. Cada vez es más territorial, más apegado a la identidad propia, como vecinos, miembros de una cultura, de una etnia, de una nación. Es este el lugar en el que se desarrolla la trayectoria delictiva, pero también es el espacio de la intervención social y donde se desarrollan las políticas sociales de proximidad que favorecen la convivencia y la integración sobre la base de un territorio.

Sostienen Subirats et al. (2008) que hablar de inclusión social es hablar de ciudadanía. La inclusión social y la ciudadanía operan con lógicas distintas, pero estrechamente vincu- 
ladas, y una es condición y posibilidad de la otra. En sus cruces, limitaciones y dinámicas se produce la exclusión y mediante la intervención transformadora puede tejerse la inclusión social. Y esta clave sólo puede realizarse desde políticas y programas de proximidad pensados desde y para el territorio.

Actualmente, las políticas urbanas tratan de hacer frente a los problemas de segregación y degradación de los barrios, sin embargo, algunas de las estrategias políticas tendentes a atraer capital para convertir a la ciudad en un centro con visibilidad internacional, refuerzan, según algunos estudios (Smith, 1996) los procesos de segregación y exclusión social. Hay que tener en cuenta, que esta segregación social y territorial es, a veces, reforzada por la percepción que la población tiene sobre las distintas zonas de la ciudad. La fractura social, agudizada por una imagen mental negativa, incide especialmente sobre la población más joven.

De hecho, distintos estudios científicos evidencian que vivir en un barrio desfavorecido presenta efectos negativos que merman la calidad de vida de sus residentes y de sus oportunidades de vida, especialmente entre los colectivos más jóvenes. Para Herin (2008) estos barrios marcan las personalidades de sus residentes que les conduce a la auto-exclusión y condiciona sus relaciones sociales con el resto de los residentes de la ciudad que rehúyen esos territorios por miedo o temor a sus residentes.

En el plano de la delincuencia y su relación con el territorio, cabe citar las investigaciones de Thrasher en 1927 sobre las bandas juveniles y el territorio, la de Shaw y Mckay en 1929 (cit. en Picó y Serra, 2010) que llevaron al extremo el análisis espacial sobre las áreas delictivas de Chicago llegando a la conclusión que las características físicas de la zona causan la delincuencia, es decir los jóvenes delincuentes no se diferencian sustancialmente de los no delincuentes en sus características de personalidad, inteligencia u otras, sino en los tipos de barrios en los que viven. Determinados barrios ofrecen más oportunidades para la actividad delictiva y en ellos el comportamiento de algunos jóvenes se aprende y transmite por vía de tradición, consolidándose cuando el individuo se identifica con su mundo delictivo (Picó y Serra, 2010).

Por tanto, y desde estos postulados asumimos que la trayectoria delictiva se encuentra vinculada a la vulnerabilidad social y exclusión social y ésta al territorio. Y un elemento fundamental para la intervención en el territorio es la accesibilidad y proximidad de las estructuras de intervención de las personas y entornos en los que se han de desarrollar los procesos.

\section{II.3.Adolescentes vulnerables, adolescentes en conflicto con la ley}

El concepto de vulnerabilidad social está tomando una relevancia cada vez mayor, ya que, entre otras cosas, atiende bien a las dinámicas que están surgiendo en las sociedades más avanzadas en estos últimos años (Sáez, Pinazo y Sánchez, 2008). Zarzuri (2000) revela que los factores de vulnerabilidad en los adolescentes están más relacionados con las contingencias vinculadas a las causas que generan el riesgo (residir en un barrio con elevada tasa de paro y ociosidad), que con el riesgo en sí mismo (el paro / la ociosidad). Desde esta perspectiva, el tiempo de exposición al riesgo configurará el grado de vulnerabilidad al que se ha sometido un individuo, sobre el que la exclusión diseñará su particular plan de desgaste. 
Los ACL forman parte de la comunidad. No son diferentes de otros adolescentes vulnerables, se diferencian en que además han cometido delitos y han sido enjuiciados. La propia acción de la justicia juvenil constituye un factor de vulnerabilidad (Uceda, 2011). La justicia dispone de competencias tanto en la protección de menores (control judicial de las actuaciones administrativas, establecimiento de custodias familiares, etc.), como en las situaciones de conflicto (o más conocido como reforma) con menores. En éstas últimas, su actuación se produce en los juzgados de menores con los adolescentes que han cometido infracciones entre los 14 y 18 años. Nuestro modelo de atención a los ACL se sustenta en las recomendaciones internacionales (Reglas de Beijing, Directrices de Riad, Reglas de la Habana y Reglas de Tokio), donde, en síntesis, se reconoce la delincuencia juvenil como un fenómeno global y que, por tanto, requiere una regulación en su prevención y tratamiento así como impulsar un modelo de justicia juvenil que posibilite la participación e inserción de/en la comunidad (González-Tascón, 2010).

La aprobación de la Ley 5/2000, reguladora de la Responsabilidad Penal de los Menores, que entró en vigor en el año 2001 (en adelante LORPM) supuso asumir como ejes sustantivos en España: a) el interés superior del menor, es decir el libre desarrollo de su personalidad, de su educación, integración social, etc., valorados por los equipos profesionales; b) responsabilidad del menor sobre los hechos, de acuerdo con la tipicidad establecida en el código penal y leyes especiales y c) la participación y reinserción en la comunidad. Para la consecución de la finalidad establecida la LORPM arbitra medidas privativas y no privativas de libertad.

Los últimos estudios sobre jóvenes delincuentes, defienden la necesidad de facilitar los procesos de reinserción a través de la aplicación por parte de los tribunales, de medidas preferentemente de tipo comunitario frente a las de internamiento, ya que se logra reducir claramente el riesgo delictivo y las tasas de reincidencia (Redondo, et al., 2011).

Partimos de la premisa que garantizar el interés superior del menor, no sólo depende del tipo de medida y tratamientos terapéuticos individualizados que se apliquen, sino, en gran medida, está sujeto a la accesibilidad en la intervención, es decir, la proximidad del equipo de referencia o del centro de reeducación en el que se desarrolla la intervención profesional. Esta proximidad de la intervención es especialmente importante para los ACL cuya situación de vulnerabilidad y exclusión social es mayor.

La localización y las características del territorio (barrios/distritos) resultan ser de gran interés y aplicación en la gestión de la intervención social y, en definitiva, en la mejora de la calidad de vida de los ciudadanos. A continuación, presentamos un análisis para el caso de la ciudad de Valencia, de los ACL objeto de intervención mediante medidas de medio abierto, con el fin de proponer mejoras de localización de los centros de intervención para conseguir una justicia juvenil que, como indican las recomendaciones internacionales señaladas, garantice la inserción de los jóvenes en su entorno y eviten la desestructuración familiar y la pérdida de redes sociales en un entorno conocido y cercano.

\section{METODOLOGÍA. TRAYECTORIAS Y ESCENARIOS}

El planteamiento metodológico se desarrolla alrededor de dos conceptos fundamentales: trayectorias (adolescentes) y escenarios (territorio), ya que permiten articular la diver- 
sidad y complejidad de la sociedad actual con el fenómeno de la delincuencia juvenil. Esta investigación se desarrolla en la ciudad de Valencia, que por tamaño y actividad, reúne las condiciones para abordar el fenómeno desde la dimensión local. La ciudad, en tamaño poblacional, es la tercera del Estado Español, y muestra perfectamente los cambios sociales acaecidos a partir de la última década del siglo XX en las sociedades postindustriales (Azagra y Romero, 2007).

Dada la complejidad de la investigación se ha preferido como estrategia la complementariedad metodológica, utilizándose diferentes técnicas cuantitativas y cualitativas: el análisis de fuentes secundarias (estadísticas socio-económicas sobre la ciudad de Valencia), primarias (expedientes del juzgado de menores y encuesta a la población ${ }^{2}$ ), cuyos resultados se han tratado con SPSS16; las entrevistas focalizadas con el MAXqda2007 y el cálculo de la accesibilidad a los centros de servicios de intervención (Equipo de Intervención de Medio Abierto y Centros de Reeducación de Referencia) a través de la red pública de transporte mediante un SIG.

Se ha tomado como referencia el año 2006 en la ciudad de Valencia ${ }^{3}$. Durante el ejercicio 2006, han sido derivadas al programa de medidas judiciales del Ayuntamiento de València un total de 422 medidas $^{4}$, entre cautelares y firmes; de ellas, 192 han recaído en ACL con los que ya se venía trabajando en años anteriores, mientras que las 230 medidas restantes corresponden a nuevos ACL (aunque también había medidas que implicaban al mismo ACL). Así, se generó una base de datos con los 286 ACL (100\% del ejercicio 2006).

A partir de los datos estadísticos, se han construido tres tipologías de trayectorias delictivas: a)ACL de trayectoria delictiva inicial (ACLTI), correspondiente al primer tercil, son 94 casos y su trayectoria delictiva se encuentra definida por haber cometido un delito, tener un tipo de medida y únicamente haber pasado por un juzgado; b)ACL de trayectoria delictiva moderada (ACLTM), correspondiente con el segundo tercil, son 97 casos y su trayectoria delictiva se ha concretado en haber pasado por 1,5 juzgados (es decir, tan habitual es haber pasado por uno como por dos) y haber cometido dos delitos pero el tipo de medida impuesta es una; y c) ACL de trayectoria delictiva consolidada (ACLTC), correspondiente con el tercer tercil, son 90 casos, han pasado por cuatro juzgados, han cometido cuatro delitos y el tipo de medida impuesta son tres diferentes ${ }^{5}$.

El análisis de fuentes primarias y el tratamiento con SPSS se ha complementado con 32 entrevistas focalizadas a profesionales de los diferentes centros y del equipo de medio abierto de Valencia. Se ha seguido el modelo de Patton (1990), de entrevista basada en guión, caracterizada por la preparación previa de los temas a tratar y por tener el entrevistador libertad para obtener y formular las preguntas y diseñado desde los tres principios muéstrales de heterogeneidad, accesibilidad y representación (Valles, 1999).

2 Ver ANEXO para características de la encuesta.

3 La provincia de Valencia, en cuestiones criminológicas en la jurisdicción de Menores, para el ejercicio analizado es la tercera respecto al número personas a los que se les ha aplicado la Ley 5/2000, que han sido a un total de 16.568 menores; en el conjunto del Estado Español la cifra es de 95.299 menores. Representa el 17,38\% de los expedientes de ACL en el 2008 en la memoria de la Fiscalía General del Estado.

4 Memoria Equipo Medidas Judiciales. Año 2006. Concejalía de Bienestar Social e Integración. Ayto València.

5 Estos datos forman parte del trabajo de campo de la tesis doctoral de Uceda (2011). 


\section{LOS RESULTADOS}

\section{IV.1. La ciudad de Valencia. Cartografía de la desigualdad}

\section{IV.1.1. Condiciones de vida y características de los distritos}

La ciudad de Valencia cuenta en la actualidad con una población de 798.033 habitantes (2011), siendo el centro de un área metropolitana que incluye otros 75 municipios y una población total próxima a los 2 millones de habitantes. La superficie ocupada por la ciudad es de 134,6 km², lo que supone una densidad de población de casi 6.000 habitantes por kilómetro cuadrado, muy por encima de la media de su área metropolitana $\left(851 \mathrm{hab} / \mathrm{km}^{2}\right)$. La ciudad de Valencia se estructura en 19 distritos con 88 barrios.

La ciudad presenta diferencias territoriales importantes, como es de esperar en un centro urbano de este tamaño que, además, se estructura, desde el punto de vista urbanístico, como el centro de una gran área metropolitana urbana con ciudades importantes como Torrent, Paterna, Mislata o Burjassot, entre otras, poblaciones que se confunden con la de la capital por formar un espacio continuo de vida, trabajo y ocio.

La población por distritos es muy variable, como lo es la extensión y nivel de ocupación del suelo de los mismos. Cabe destacar que entre 1991 y 2012 son los distritos periféricos los que han crecido en población, puesto que en ellos se ha producido una importante expansión urbanística (gráfica 1). El centro de la ciudad, incluido el primer ensanche, han perdido población ligeramente.

Otras variables que caracterizan la urbe desde el punto de vista socioeconómico, nos indican diferencias entre distritos, pero sin determinar claramente diferencias radicales entre ellos. Dichas diferencias podrían detectarse con más detalle en un análisis por barrios, sin embargo, la información disponible actualizada no se encuentra a ese nivel territorial, lo cual unido a la necesidad de mantener el secreto estadístico en los datos sobre ACL, nos obliga a realizar el análisis por distritos. A pesar de este leve inconveniente, los resultados no dejan de ser interesantes.

El crecimiento poblacional se da, particulamente, en la primera periferia, especialmente del norte (mapa 1). Sin embargo, los distritos con mayor porcentaje de población inmigrante se encuentran, en la actualidad, en el sur de la ciudad (mapa 2). Las nuevas urbanizaciones del norte, con un claro incremento de los precios del suelo, explican el bajo porcentaje de población inmigrante, que, por otra parte tiende a agruparse en zonas donde residen familiares o conocidos.

Otros aspectos como las tasas de paro y el analfabetismo funcional (mapas 3 y 4), nos dan una imagen diferente de los distritos de la ciudad. Por una parte, el paro afecta, actualmente, a todos los espacios urbanos. En la ciudad el paro asciende a algo más del 18\%, y sólo 6 distritos se encuentran por debajo de esta cifra, todos ellos del centro o de la primera periferia. Las zonas más alejadas del centro presentan cifras más elevadas, con tasas, en los casos más extremos, por encima del $20 \%$.

La población con los niveles socioprofesionales de menor cualificación se sitúa en las periferias y extensiones suburbanas. Se trata de barrios o distritos construidos desde los años 40 hasta los 70, en algunos casos, son zonas aisladas con deficiencias urbanísticas y cono- 
Gráfica 1

EVOLUCIÓN DE LA POBLACIÓN POR DISTRITOS. 1991-2012

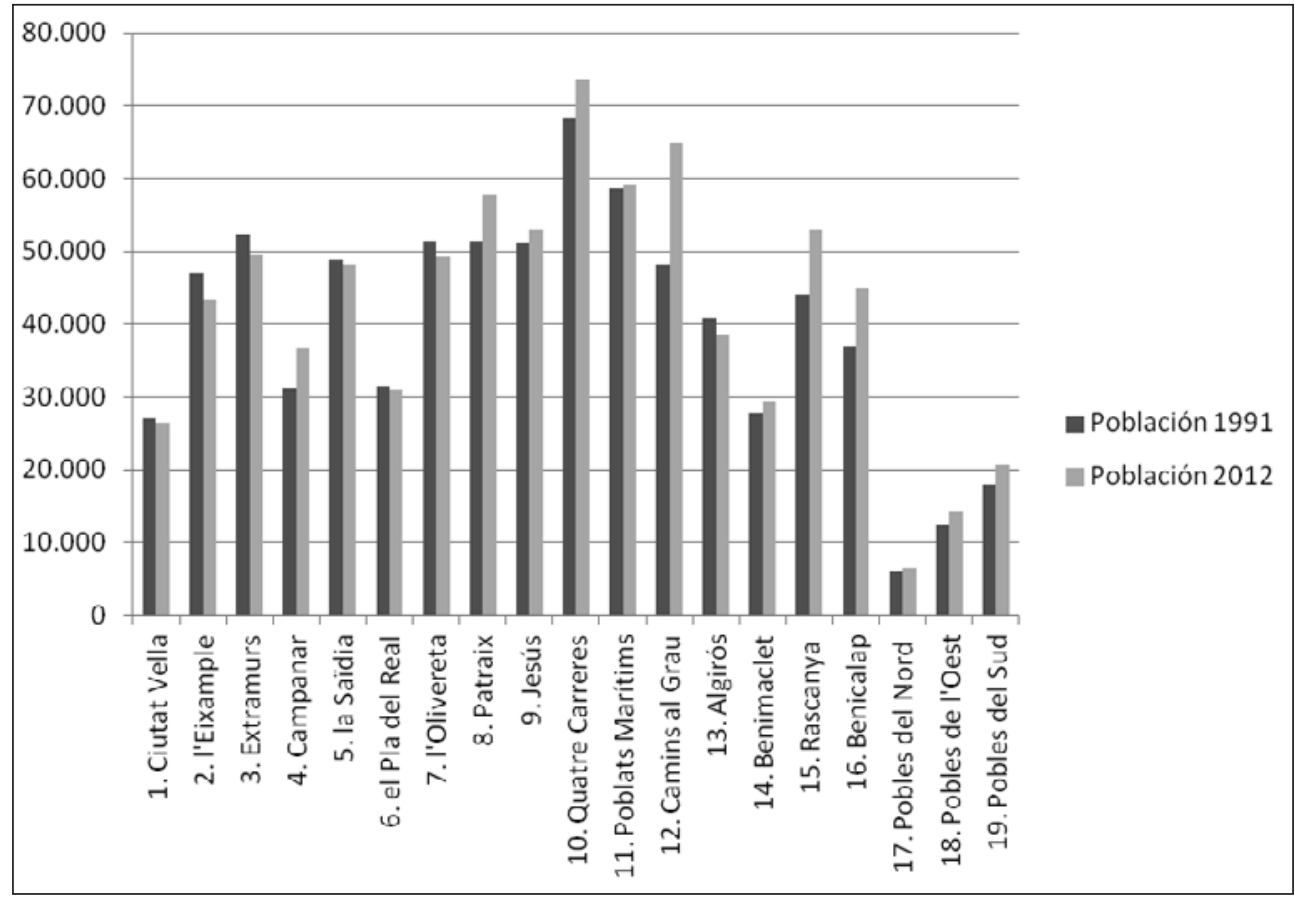

*Los distritos 10, 11, 15, 16 y 17 cambiaron su delimitación territorial en el Pleno del Ayuntamiento de 31/01/2003. Fuente: Elaboración propia a partir de datos de Oficina Estadística del Ayto València.

cidos problemas sociales. Los distritos con las tasas de paro más elevadas coinciden, en su mayoría, con analfabetismo funcional elevado y precios del suelo bajos. En algunos distritos de la segunda periferia se dan situaciones intermedias, con mayor mezcla de situaciones, mientras que en el centro de la ciudad las condiciones socioeconómicas son claramente favorables y en la periferia exterior claramente desfavorables.

En cuanto a las actividades profesionales de los residentes, destacan las relacionadas con las finanzas en el centro de la ciudad, mientras que en la periferia son más importantes las relacionadas con la industria y la construcción, claramente por encima de la media de la ciudad. Lo mismo ocurre con los trabajadores de la agricultura, que, aunque son una minoría, se agrupan sobre todo en la periferia norte y oeste de la ciudad.

El Ayuntamiento de València ha desarrollado un indicador del nivel de renta de los distritos y barrios de la ciudad, calculado para los años con información censal. Es un indicativo tendencial que puede servir para una primera caracterización de este territorio ${ }^{6}$. Según este

6 Última actualización 2001; partiendo de la hipótesis de que aunque todavía no se encuentra actualizado es válido, ya que la actual situación socioeconómica de la ciudad implica que haya un empobrecimiento general de ésta en los últimos años. 


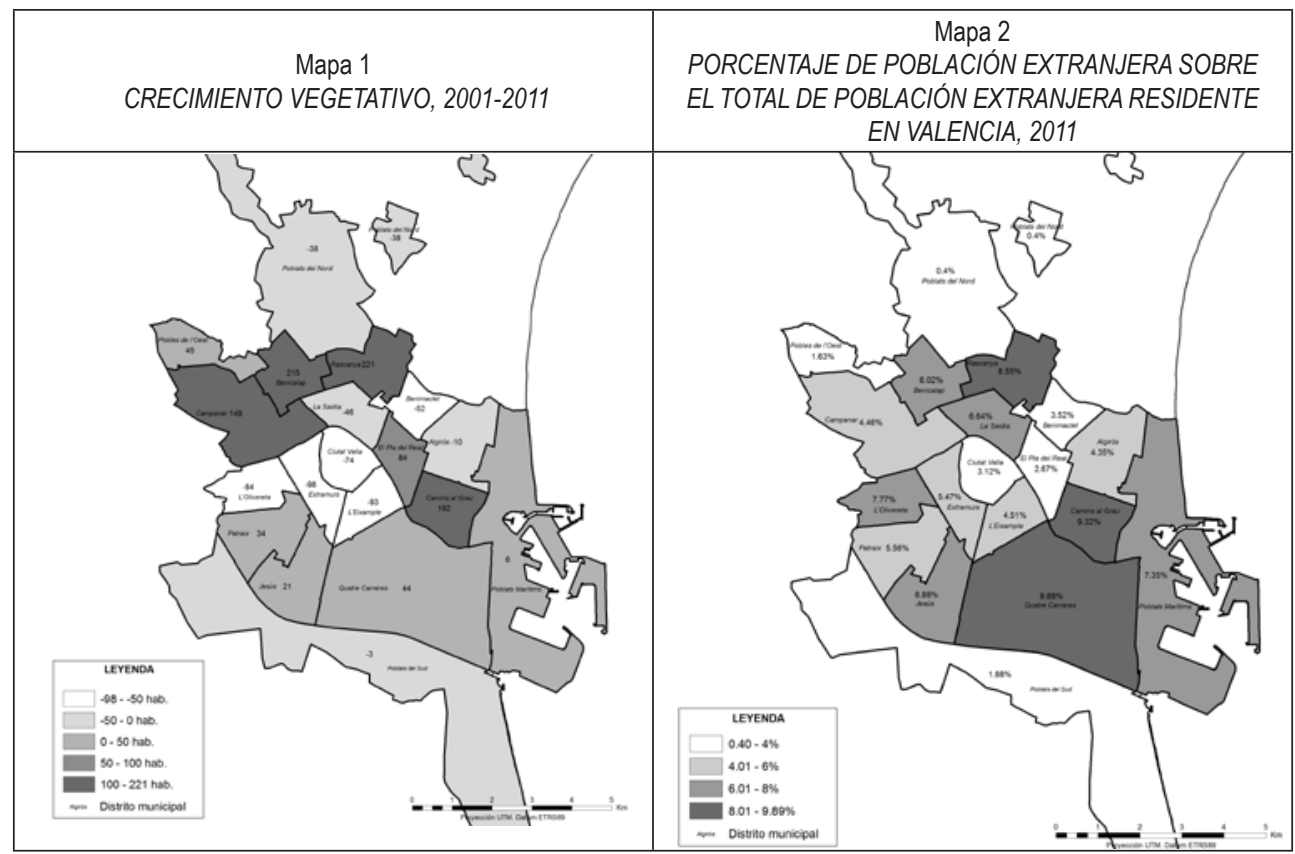

Fuente: elaboración propia a partir de datos de Oficina Estadística del Ayto. València.

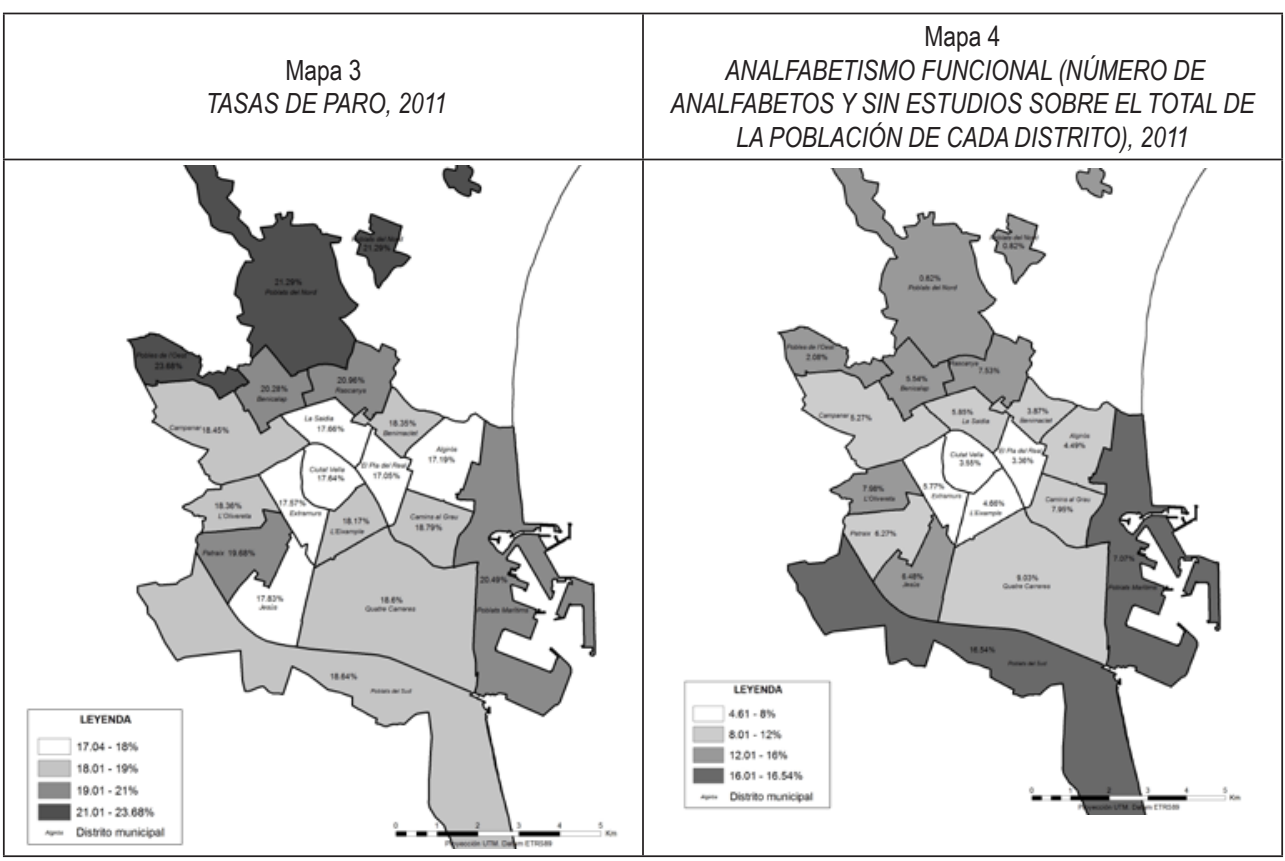

Fuente: elaboración propia a partir de datos de Oficina Estadística del Ayuntamiento Valencia. 
indicador, elaborado por la Oficina de Estadística del Ayuntamiento de València ${ }^{7}$ desde 1984, en 2001, 7 de los 19 distritos de la ciudad presentan un resultado negativo, es decir, son clasificados como de renta media-baja o baja (tabla 1). En 2011, con datos del propio Ayuntamiento, disponibles a través de su servicio de Estadísticas (mapa 5), hemos realizado una clasificación similar, dando como resultado algunos cambios en la situación de los distritos, en particular de los periféricos que ven mejorado su nivel de renta, resultado lógico que se explica por la construcción de nuevas zonas residenciales que atraen población con mayor nivel económico, mientras que en zonas de antigua urbanización como L'Olivereta, Poblats Maritims, Rascanya o Pobles de l'Oest la situación económica se mantiene estable baja o empeora. En definitiva, existen claras diferencias en la realidad socioeconómica actual de los distritos de la ciudad de Valencia (mapas 5 y 6) y éstas se explican, en gran parte, por la evolución urbanística de los mismos así como por el desarrollo económico de unos años marcados por la recesión y la recuperación (desde los 80 hasta la actualidad) que han contribuido a consolidar algunas zonas como las de mayor concentración de familias de renta baja, mientras que otras han mejorado su posición atrayendo a familias de renta media o alta a la vez que desplazaban a las más humildes a barrios o zonas degradadas e incluso fuera de la ciudad, hacia municipios y barrios de la periferia metropolitana.

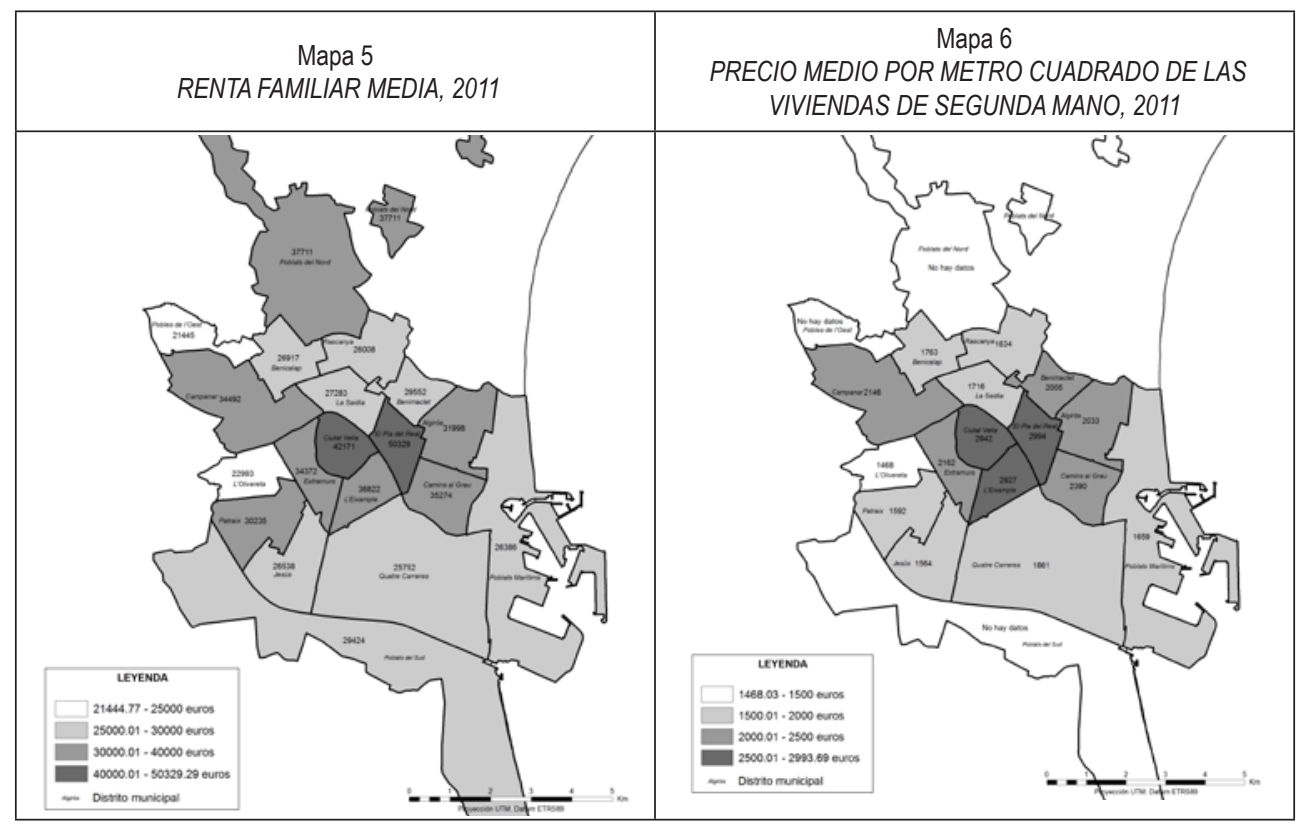

Fuente: Elaboración propia a partir de datos de Oficina Estadística del Ayuntamiento de Valencia.

7 Oficina de estadística de la ciudad de Valencia. Oficina de estudios. «Aproximación a un indicador del nivel de renta, 1981-1991-2001» http://www.valencia.es/ayuntamiento/otras_publicaciones.nsf/vDocumentosTitulo/IndicadorRenta?opendocument\&lang=1\&bdOrigen=ayuntamiento/estadistica.nsf\&lang=1\&nivel=8 
Tabla 1

NIVELES DE RENTA EN LOS DISTRITOS DE LA CIUDAD DE VALENCIA

\begin{tabular}{|l|l|l|l|l|}
\hline Distrito & 1981 & 1991 & 2001 & $2011^{*}$ \\
\hline 1. Ciutat Vella & Alto & Alto & Alto & Alto \\
\hline 2. l'Eixample & Alto & Alto & Alto & Alto \\
\hline 3. Extramurs & Alto & Alto & Medio-alto & Medio-alto \\
\hline 4. Campanar & Medio & Medio & Medio & Medio-alto \\
\hline 5. La Saïdia & Medio & Medio & Medio & Medio \\
\hline 6. El Pla del Real & Alto & Alto & Alto & Alto \\
\hline 7. L'Olivereta & Medio-bajo & Medio-bajo & Medio-bajo & Bajo \\
\hline 8. Patraix & Medio & Medio & Medio & Medio-alto \\
\hline 9. Jesús & Medio & Medio & Medio-bajo & Medio-bajo \\
\hline 10. Quatre Carreres & Medio & Medio & Medio & Bajo \\
\hline 11. Poblats Marítims & Medio-bajo & Bajo & Bajo & Medio-bajo \\
\hline 12. Camins al Grau & Medio & Medio & Medio-bajo & Alto \\
\hline 13. Algirós & Medio & Medio & Medio-alto & Medio-alto \\
\hline 14. Benimaclet & Medio-bajo & Medio & Medio & Medio \\
\hline 15. Rascanya & Medio-bajo & Medio-bajo & Bajo & Bajo \\
\hline 16. Benicalap & Medio & Medio-bajo & Medio-bajo & Medio-bajo \\
\hline 17. Pobles del Nord & Medio & Medio-bajo & Medio & Alto \\
\hline 18. Pobles de l'Oest & Bajo & Bajo & Medio-bajo & Bajo \\
\hline 19. Pobles del Sud & Medio-bajo & Medio-bajo & Medio & Medio \\
\hline
\end{tabular}

*Clasificación propia a partir de los datos de renta familiar media, 2011.

Fuente: elaboración propia a partir de datos de Oficina Estadística del Ayuntamiento de Valencia.

Los conocidos como «efectos de barrio» son, como se ha señalado anteriormente, difíciles de determinar. En la ciudad de Valencia, los barrios periféricos más degradados durante los 70 y 80 del siglo pasado, han experimentado un proceso de crecimiento y renovación asociado a los nuevos procesos de urbanización que ha originado una mezcla de grupos sociales más heterogénea que en la etapa anterior. Ello ha supuesto escasos desplazamientos asociados al aumento del precio del suelo tanto en el centro como en la periferia de la ciudad. Cabe recordar que el enfoque territorial del presente artículo no debe ser entendido ni como el único ni como el principal para explicar el «efecto barrio». Es evidente que las oportunidades de mejora de la calidad de vida de las personas, en particular de los jóvenes, no dependen sólo de la zona de residencia y del estatus socioeconómico (muchas veces relacionado directamente con el barrio en el que se vive), sino también de los comportamientos personales, los valores familiares, la evolución personal del individuo, etc.

El estudio socioespacial de la ciudad de Valencia que aquí presentamos contribuye a una parte de la explicación de la aparición de la delincuencia en determinadas áreas de la ciudad, pero no puede ser la única, por tanto se trata de una perspectiva parcial que mejora la comprensión del fenómeno de la delincuencia juvenil y complementa otras perspectivas más sociológicas o comportamentales que contribuyen a la construcción de una visión holística del mismo. No es nuestra intención, como se ha señalado, explicar la delincuencia juvenil 
a partir de las características del barrio, sino contribuir al diseño de la acción pública de integración de los jóvenes delincuentes desde el territorio. Por ello, y tras el somero análisis de las características socioeconómicas de los distritos de la ciudad de Valencia, podemos concluir que no hay motivos territoriales (concentración elevada de pobreza, marginación social, desempleo, etc.) que justifiquen el alejamiento de los ACL de su entorno habitual, por lo tanto, sería, en principio, muy recomendable acercar a los barrios o distritos, en particular a los más degradados, los centros de intervención sociocomunitaria encargados de la integración social de estos jóvenes.

\section{IV.1.2. Los Adolescentes en conflicto con la ley en la ciudad de Valencia}

El impacto de la delincuencia juvenil en la ciudad de Valencia es menor que la media nacional (tabla 2). En España, según datos del Ministerio del Interior, existen 4 jóvenes delincuentes por cada 10.000 habitantes, concretamente, en 2008, el 6,5\% de los delitos fueron cometidos por menores de entre 14 y 17 años (Montero, 2007).

En el caso de Valencia, en principio, el lugar de residencia es indiferente. Se encuentran en toda la ciudad, aunque algunas áreas concentran un mayor número, incluso en términos relativos. En la tabla 2 se observa, además de algunas características indicativas de las condiciones socioeconómicas de los distritos, que sólo dos de los diecinueve suman el 30\% de los ACL y siete distritos el 60\%. Existen algunos en los que, en el año considerado, no hay ningún caso (Pobles del Nord) y distritos con porcentajes muy elevados, como Quatre Carreres, que concentra el $16 \%$ de todos los ACL de la ciudad.

Desde el punto de vista territorial, los ACL se caracterizan por la dispersión y la concentración, es decir están presentes en 18 de los 19 distritos. No están presentes (o de forma inapreciable) en los distritos de: Poblats del Nord, Poblats del Sud y Pobles de l'Oest, que se corresponde con pedanías de la ciudad de València, es decir barrios pequeños, de población mayor, que no han sufrido transformaciones urbanísticas ni sociales desde mitad del siglo pasado. Dentro de los distritos con poca presencia, se encuentra el Pla del Real, de alto poder adquisitivo, y Ciutat Vella, inmersa en un proceso de transformación en los últimos años, caracterizada por población diversa pero ajena al fenómeno: en unos casos por su alto poder adquisitivo, en otros por ser población envejecida y finalmente, por la población joven (de edades de más de 20 a 30 años y de clase media) que llega fruto del proceso de revitalización de estos barrios históricos. Los distritos con presencia muy significativa son L'Olivereta, Poblats Marítims y Quatre Carreres, distritos que albergan a población de clase trabajadora y en la que existen barrios que concentran núcleos de exclusión social, muy identificados por los servicios sociales de la ciudad (tabla 2 y mapa 7 ).

Respecto a la ubicación espacial de las trayectorias delictivas, es decir de los ACLTI, ACLTM y ACLTC, observamos que se produce una concentración muy significativa en los mismos distritos de la ciudad de Valencia en las tres trayectorias: L'Olivereta, P. Marítims y Quatre Carreres (mapa 8). Estos distritos suponen en cada una de las trayectorias en torno al 40\% y 50\% de los ACL. Las trayectorias delictivas se consolidan en los mismos distritos. Esta concentración supone que son distritos donde se desarrolla la trayectoria delictiva de los ACL desde su inicio a su consolidación; en este sentido los ACL que consolidan trayectoria delictiva son los candidatos a entrar en el centro penitenciario (Uceda, 2011). 
Tabla 2

ELEMENTOS SOCIOECONÓMICOS Y ADOLESCENTES EN CONFLICTO CON LA LEY (ACL) SEGÚN DISTRITOS. VALENCIA

\begin{tabular}{|l|c|c|c|c|c|c|}
\hline & $\%$ ACL & $\begin{array}{c}\text { Tasa de } \\
\text { paro } 2011\end{array}$ & $\begin{array}{c}\text { Índice } \\
\text { demográfico } \\
\text { de } \\
\text { dependencia }\end{array}$ & $\begin{array}{c}\text { \% hogares } \\
\text { unipersonales } \\
\text { de mayores de } \\
65 \text { años. 2012 }\end{array}$ & $\begin{array}{c}\text { Edad media } \\
\text { de las } \\
\text { viviendas, } \\
2012\end{array}$ & $\begin{array}{c}\text { ACL por cada } \\
\text { 10.000 hab. } \\
\text { (pobl. 2007) }\end{array}$ \\
\hline Valencia & $98 \% 8$ & 19 & 50,12 & 61,49 & 38,9 & 3,57 \\
\hline 1. Ciutat Vella & $2 \%$ & 18 & 49,09 & 42,58 & 65,2 & 1,97 \\
\hline 2. l'Eixample & $3 \%$ & 18 & 58,22 & 61,16 & 62,1 & 2,27 \\
\hline 3. Extramurs & $3 \%$ & 18 & 57,10 & 63,94 & 52,6 & 1,80 \\
\hline 4. Campanar & $4 \%$ & 18 & 47,53 & 56,67 & 27,7 & 3,16 \\
\hline 5. la Saïdia & $7 \%$ & 18 & 54,48 & 68,80 & 38,1 & 3,85 \\
\hline 6. el Pla del Real & $1 \%$ & 17 & 58,02 & 66,60 & 36,3 & 1,28 \\
\hline 7.1'Olivereta & $10 \%$ & 18 & 55,71 & 71,64 & 38,8 & 5,58 \\
\hline 8. Patraix & $6 \%$ & 20 & 46,69 & 62,75 & 31,5 & 2,74 \\
\hline 9. Jesús & $5 \%$ & 18 & 45,66 & 63,60 & 34,4 & 2,42 \\
\hline 10. Quatre Carreres & $16 \%$ & 19 & 51,20 & 66,43 & 34,1 & 6,17 \\
\hline 11. Poblats Marítims & $13 \%$ & 20 & 49,52 & 62,38 & 41,6 & 6,46 \\
\hline 12. Camins al Grau & $7 \%$ & 19 & 48,93 & 57,07 & 31,1 & 3,00 \\
\hline 13. Algirós & $5 \%$ & 17 & 44,85 & 58,27 & 32,6 & 3,43 \\
\hline 14. Benimaclet & $3 \%$ & 18 & 43,97 & 55,55 & 33,8 & 2,63 \\
\hline 15. Rascanya & $5 \%$ & 21 & 48,35 & 62,39 & 32,1 & 2,89 \\
\hline 16. Benicalap & $5 \%$ & 20 & 46,21 & 57,68 & 29,6 & 3,27 \\
\hline 17. Pobles del Nord & $0 \%$ & 21 & 55,59 & 64,19 & 47,2 & 1,59 \\
\hline 18. Pobles de l'Oest & $2 \%$ & 24 & 46,24 & 56,92 & 34,7 & 5,03 \\
\hline 19. Pobles del Sud & $1 \%$ & 19 & 47,07 & 60,89 & 38,0 & 1,96 \\
\hline
\end{tabular}

Fuente: elaboración propia a partir de datos de Oficina Estadística del Ayuntamiento de Valencia.

La mayor parte de los ACLs, además de residir en barrios con características que favorecen la exclusión (paro, dependencia, baja renta, etc.), presentan características personales que les dificultan aún más la inclusión social (tabla 2). El 23\% de los mismos son inmigrantes, el $22 \%$ pertenecen al pueblo gitano, el $87 \%$ sin estudios obligatorios terminados (por abandono) (teniendo en cuenta que el $12 \%$ no consta, la cifra podría ser muy superior), para el $53 \%$, sus padres tienen empleos no cualificados (si tenemos en cuenta que en el $43 \%$ de los casos no consta la profesión del padre, la cifra podría llegar hasta el 95\%), y para el 9\% sus padres son jubilados, el 5\% desempleados y el 9\% con ocupación irregular. Además, el 19\% son reincidentes, a los que habría que sumar el $35 \%$ que acumulan medidas, y sobre el $40 \%$ existen medidas

8 Del $2 \%$ restante son ACL, que en sus expedientes no figuraba localización, bien porque no habían llegado a residir en la ciudad y su caso se había derivado a otros municipios, bien porque su domicilio era desconocido, etc. 


\section{Mapa 7}

INCIDENCIA DE LAACL CADA 1000 ADOLESCENTES (14-18 AÑOS) POR DISTRITOS EN VALENCIA, 2006

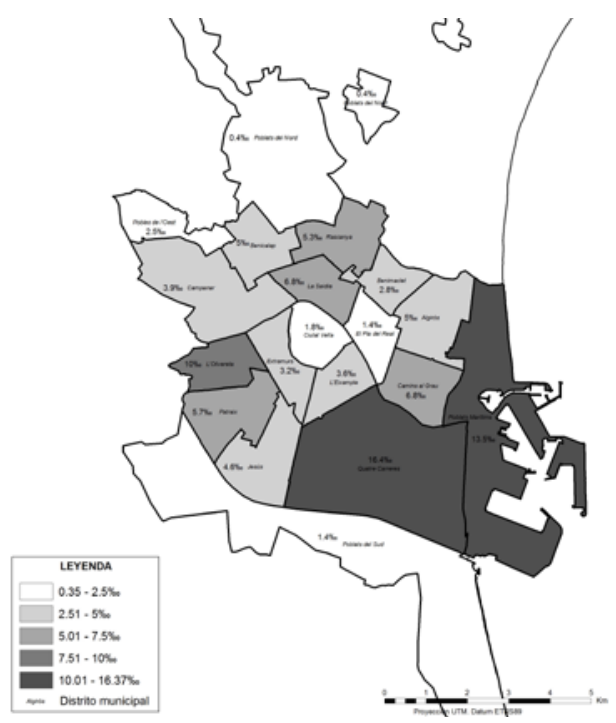

Fuente: elaboración propia a partir de Uceda (2011).

Mapa 8

INCIDENCIA DE LAACL SOBRE EL TOTAL DE LA CIUDAD, POR DISTRITOS Y TIPO DE TRAYECTORIA DELICTIVA, 2006

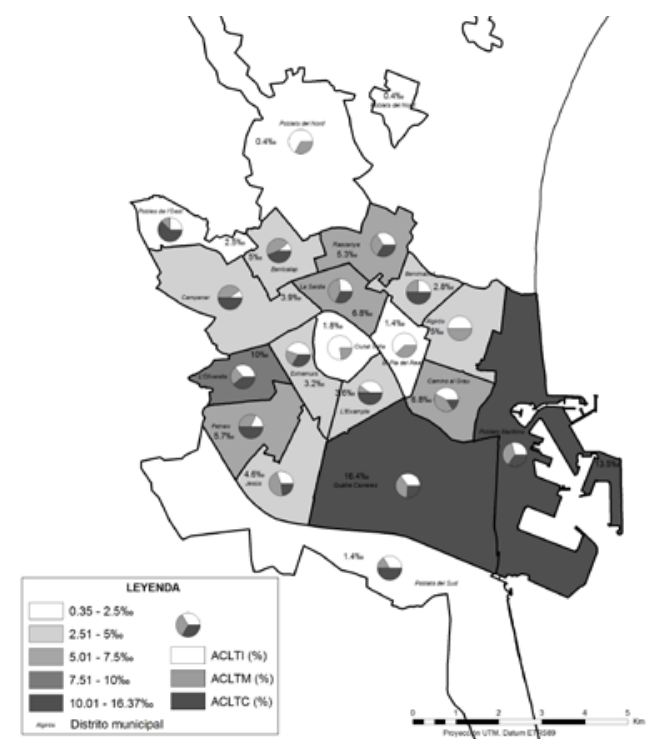

Fuente: elaboración propia a partir de Uceda (2011). 
cautelares, el 30\% de las mismas supone internamiento y el 10\% libertad vigilada. En este contexto, es fundamental la proximidad a los centros, ya sean de medio abierto o cerrado, pues la distancia forma parte de la exclusión social y dificulta la intervención y el acompañamiento que estos jóvenes precisan.

\section{IV.1.3. La percepción de la ciudad por parte de sus ciudadanos}

Según las encuestas del CIS entre 2002 y 2003, el problema de la inseguridad ciudadana y la delincuencia en general era percibido por el $25 \%$ de los ciudadanos aproximadamente como uno de los tres problemas principales de España. En la actualidad sólo el $3 \%$ lo valora así. Las diferencias en la opinión pública no reflejan la realidad, sino la percepción de la misma, pues el número de delitos y faltas por cada 1000 habitantes se ha mantenido más o menos estable entre el año 2000 y la actualidad, con cifras alrededor de 45, aunque se dio un leve incremento hasta 52 en el año 2002, fecha desde la que ha ido disminuyendo, pero mucho más levemente que la percepción de la problemática sobre la delincuencia ${ }^{9}$.

A pesar de ello, y siguiendo los estudios que se han realizado, es importante conocer cómo valoran los ciudadanos el entorno en el que viven y poder, así, relacionar esa valoración con la existencia de un mayor o menor número de ACL. Para conocer la valoración de la población sobre su barrio o ciudad, nos basamos en una encuesta reciente realizada por nuestro equipo de investigación en el Área Metropolitana de Valencia ${ }^{10}$.

Según la encuesta realizada, la mayor parte de la población de la ciudad de Valencia valora positivamente su barrio de residencia y dice sentirse «a gusto o muy a gusto» en la misma. No obstante, en algunos distritos, y coincidiendo precisamente, con los anteriormente señalados como más problemáticos, la percepción de la población no es tan positiva, aumentando el porcentaje de personas que lo consideran problemático y/o peligroso (tabla 3 ).

La percepción de la ciudad y del entorno del barrio es, en las áreas más vulnerables, peor que en el resto. En la actualidad, continúan siendo estos distritos los que acumulan un número más grande de problemas y así es percibido por la población residente. La delincuencia, la escasez de zonas verdes, los ruidos y la contaminación, son los más importantes, por este orden, siendo las malas comunicaciones destacables solo en Malilla (dist. Quatre Carreres), precisamente una de las zonas más aisladas de la ciudad no sólo en cuanto a infraestructuras, sino también en cuanto a oferta de transporte público. De todas maneras, la situación ha variado notablemente en la última década y es de esperar que mejore como consecuencia de la reciente construcción del hospital de referencia más grande de la Comunidad Valenciana (Nuevo Hospital La Fe).

En definitiva, las diferencias entre los barrios o distritos son importantes, destacando los distritos de l'Eixample, Pla del Real y Ciutat Vella (solo una parte) como las mejor posicionadas, en cuanto a nivel de renta y percepción de la población, quedando los barrios periféricos de Na Rovella (dist. Quatro Carreres), Tres Forques y La Fontsanta (dist. L’Olivereta) y Natzaret (dist. Poblats Marítims) como los más vulnerables o con mayor concentración de situaciones-problema.

9 Balance 2010, Evolución de la Criminalidad, Gabinete de estudios del Ministerio del Interior. http://www. interior.gob.es/file/54/54476/54476.pdf

10 Ver Anexo para características de la muestra. 
Tabla 3

NIVEL DE SATISFACCIÓN CON SU BARRIO O DISTRITO DE RESIDENCIA (\% DE RESPUESTAS SOBRE EL TOTAL DE CADA DISTRITO)

\begin{tabular}{|l|c|c|c|c|c|c|}
\cline { 2 - 7 } \multicolumn{1}{c|}{} & NS/NC & $\begin{array}{c}\text { Muy a } \\
\text { disgusto }\end{array}$ & A disgusto & Indiferente & A gusto & $\begin{array}{c}\text { Muy a } \\
\text { gusto }\end{array}$ \\
\hline Algirós & 0,00 & 0,00 & 0,00 & 0,00 & 52,63 & 47,37 \\
\hline Benicalap & 0,00 & 0,00 & 0,00 & 4,55 & 18,18 & 77,27 \\
\hline Benimaclet & 0,00 & 0,00 & 0,00 & 6,25 & 25,00 & 68,75 \\
\hline Camins al Grau & 0,00 & 0,00 & 2,94 & 0,00 & 67,65 & 29,41 \\
\hline Campanar & 0,00 & 0,00 & 0,00 & 0,00 & 0,00 & 0,00 \\
\hline Ciutat Vella & 0,00 & 0,00 & 0,00 & 7,14 & 35,71 & 57,14 \\
\hline Eixample & 0,00 & 0,00 & 4,17 & 8,33 & 37,50 & 50,00 \\
\hline Extramurs & 0,00 & 0,00 & 0,00 & 3,85 & 80,77 & 15,38 \\
\hline Jesús & 0,00 & 0,00 & 3,57 & 21,43 & 39,29 & 35,71 \\
\hline La Saidia & 3,85 & 0,00 & 0,00 & 3,85 & 73,08 & 19,23 \\
\hline Olivereta & 0,00 & 0,00 & 0,00 & 0,00 & 40,74 & 59,26 \\
\hline Patraix & 0,00 & 0,00 & 13,79 & 10,34 & 68,97 & 6,90 \\
\hline Pla del Real & 0,00 & 0,00 & 0,00 & 0,00 & 62,50 & 37,50 \\
\hline Poblats Marítims & 0,00 & 3,33 & 0,00 & 10,00 & 56,67 & 30,00 \\
\hline Quatre Carreres & 0,00 & 0,00 & 5,13 & 15,38 & 76,92 & 2,56 \\
\hline Rascanya & 3,57 & 0,00 & 0,00 & 3,57 & 60,71 & 32,14 \\
\hline Sin especificar distrito & 1,32 & 0,00 & 0,99 & 3,96 & 58,91 & 34,82 \\
\hline
\end{tabular}

Fuente: encuesta de elaboración propia 2012.

\section{IV.2. Localización de las estructuras de intervención: Equipos de Medio Abierto y Centros de Reeducación}

\section{IV.2.1. Accesibilidad objetiva. El Índice de Separación Espacial (ISE)}

En este territorio, la localización del Equipo de Medio Abierto y de los Centros de Reeducación es fundamental desde una doble perspectiva: la facilidad de los ACL para acudir al centro y la posibilidad real de los técnicos de alcanzar un territorio, y a su población para trabajar eficazmente, pues es preciso intervenir desde la proximidad y desde la lógica de inserción y participación de y en la comunidad de referencia (barrio de procedencia).

A partir del uso de software SIG $^{11}$, se ha obtenido la cartografía de la accesibilidad desde cada sección censal al Equipo de Medio Abierto y a los Centros de Reeducación. Existen 5

11 El modelo utilizado implica el cálculo de la movilidad urbana a través de las redes por las que ésta se desarrolla, es decir, se pretende una modelización lo más real posible, para lo cual nos hemos apoyado en el software de SIG para el transporte TRANSCAD 6.0. Se han considerado cuatro tipos de redes de transporte o movilidad: la red peatonal (el desplazamiento, total o en parte, del recorrido a pie), la red de autobuses urbanos y metropolitanos, la 
centros de este tipo localizados en la periferia del área metropolitana, únicamente el Equipo de Medio Abierto y un centro de internamiento se encuentran en la ciudad. Todos ellos, dan servicio a prácticamente toda la provincia, y por tanto, acogen a los ACL de la ciudad de Valencia, sea cual sea su distrito de residencia. Hemos calculado la accesibilidad de la población a cada uno de estos centros por separado, así como al conjunto de los mismos, es decir, al lugar en el que se oferta el servicio. Dicha accesibilidad se concreta en áreas de influencia teniendo en cuenta la distancia a pie o en transporte público. Para medirla se utiliza el índice llamado ISE (Índice de Separación Espacial), bien conocido y contrastado en otros estudios de accesibilidad ${ }^{12}$.

La accesibilidad de los servicios públicos, como los que aquí se analizan, debe estar garantizada para todos los ciudadanos en respuesta a la tan deseada equidad territorial y social, más aún si se trata de servicios dirigidos a personas en riesgo de exclusión. La forma en que esta equidad puede alcanzarse es doble: por una parte acercando el servicio a los ciudadanos y, por otra acercando los ciudadanos al servicio. La localización de los servicios ya está establecida y es difícil de cambiar, aunque siempre puede mejorarse. La mejor localización no siempre implica cambios en la misma, sino, en ocasiones, como se ha señalado anteriormente, una mejor accesibilidad. La mejora de la red de transporte y/o la creación de nuevas redes es hoy fundamental para integrar y ordenar las áreas urbanas y metropolitanas, en las que la dispersión y la complejidad urbanística es inevitable.

La accesibilidad es la «facilidad» con la que el usuario puede conseguir el servicio que necesita, para lo cual la accesibilidad física es importante, pero también lo es la medida de la misma en tiempo, pues, como señala Miralles (2011), los tiempos sociales (tiempos de movilidad) de la ciudad «dibujan los espacios cotidianos de las regiones metropolitanas» (p. 127). El tiempo de desplazamiento contribuye enormemente a la percepción de los ciudadanos sobre la calidad de la oferta de servicios públicos y, por tanto, sobre la calidad de la vida cotidiana. El tiempo es una medida que relaciona actividades y lugares (May y Thrift, 2001, Davovidi, 2009). Se trata del tiempo social, que aúna una variable espacial, relacionada con la localización de las actividades sobre el territorio, y una variable temporal, resultado de la utilización del tiempo en las actividades cotidianas, incluido el desplazamiento. El uso social del tiempo está, pues, íntimamente relacionado con el uso de la ciudad y del espacio metropolitano. La configuración física de dicho espacio y de las infraestructuras que soportan la movilidad condicionan las dinámicas territoriales de todo tipo y contribuye poderosamente a definir la calidad de vida de sus ciudadanos (Mückenberg, 2009, Miralles, 2011). La proximidad es un valor en alza que define la calidad territorial y el bienestar social.

red de metro-tranvía y la red de calles y carreteras para el transporte privado. En todos los casos se han considerado para las diferentes líneas de transporte las frecuencias de paso y velocidades comerciales que les son propias. De esta forma, ha sido posible que las distancias calculadas incluyan tiempos de acceso al transporte público, de espera, de transbordo entre modos, y de desplazamiento efectivo. El desplazamiento a pie se ha calculado utilizando el callejero real (el camino más corto) y no la línea recta entre origen y destino.

$12 I S E_{\mathrm{i}}=\sum_{\mathrm{j}=1}^{\mathrm{n}} \frac{\mathrm{D}_{\mathrm{ij}}}{\mathrm{n}}$, donde $i$ es la unidad espacial básica (sección censal) para el que se calcula el índice, y que se toma como posible origen de un desplazamiento; $j$ es cada uno de los potenciales lugares de destino de los desplazamientos (equipamientos); $D_{i j}$ es la distancia en minutos, -obtenida a partir de las matrices calculadas-, entre el lugar de origen i y el lugar de destino j y $n$ es el número de posibles lugares de destino. (Carrocho y Campos, 2006; Bhat et al., 2000). 
Dado que en el caso que nos ocupa los ACL son el objetivo de la intervención, el transporte público (y no el privado) se constituye en la forma principal de acercar ciudadano y servicio. El tiempo es la forma de medir la vida, en particular entre los jóvenes. En este sentido, hemos realizado los análisis de accesibilidad a cada uno de los centros y el equipo de medio abierto a pie y en transporte público. Los resultados nos indican que los centros se encuentran demasiado alejados de la población susceptible de necesitar el servicio. Todos ellos, excepto el ubicado en el barrio de El Cabanyal (dist. Poblats Marítims), se localizan fuera de la ciudad. Dado que el entramado metropolitano es especialmente denso en la primera corona, la situación mejora en gran medida si consideramos la accesibilidad en transporte público, sin embargo, aun así, quedan espacios de la ciudad de Valencia, y más aún del área metropolitana, a más de una hora andando y más de 30 minutos en transporte público, lo cual, dado que la intervención es en la mayoría de los casos diaria, dificulta el acceso de los ACL y de los profesionales al territorio de reinserción de los ACL (mapas 9 a 12).

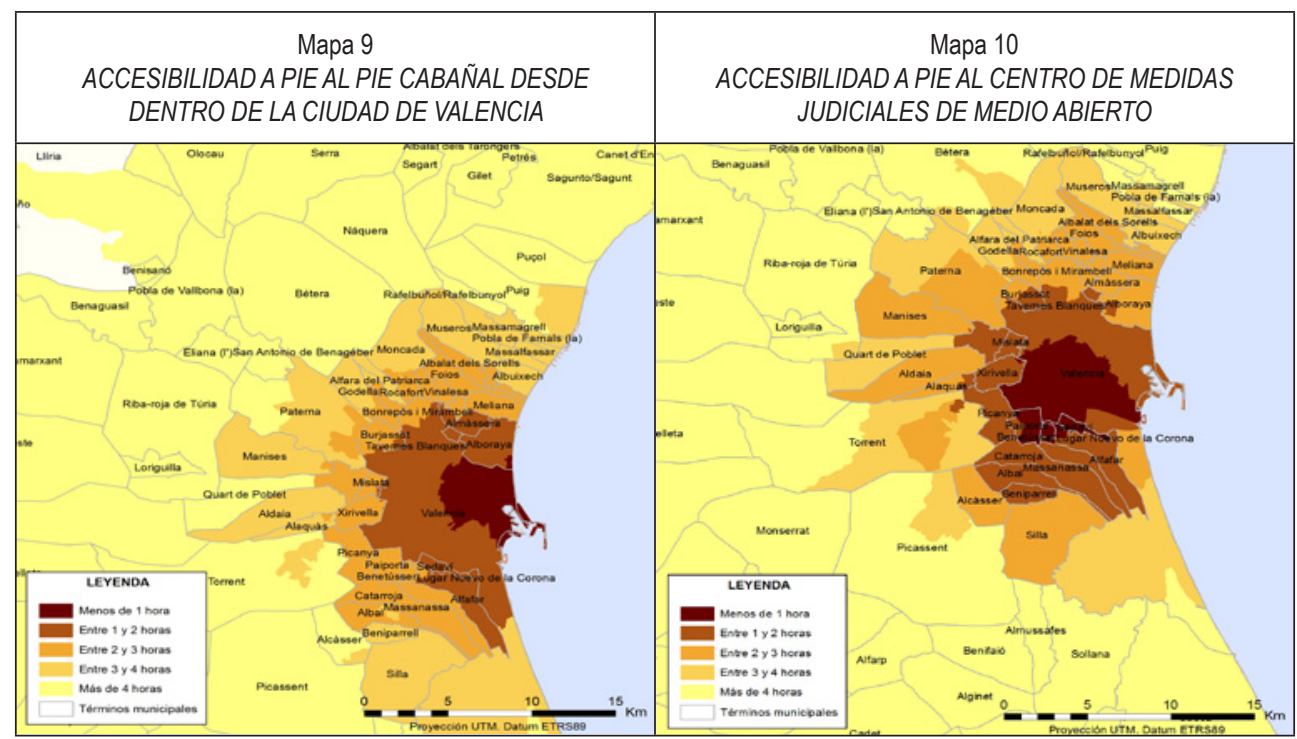

Fuente: elaboración propia.

Los mapas 13 y 14, que consideran la accesibilidad a todos los centros del área metropolitana (y por tanto adjudican la población al centro más cercano, sea del tipo que sea), nos resumen bastante claramente la situación. Aunque el área metropolitana queda peor servida, por la lejanía de casi todos los centros de población respecto a la oferta del servicio, por lo que respecta a la ciudad de Valencia, nuestra área de estudio, son distritos y barrios especialmente sensibles, como Quatre Carreres, L’Olivereta o Rascanya, los que se encuentran en peor situación, a más de dos horas andando y, en el caso de uno de los más periféricos, Rascanya, a más de una hora en transporte público. Dado que las medidas de medio abierto suponen, en la mayoría de los casos, la obligatoriedad de que el ACL acuda al centro, estas distancias no son aceptables, o, como mínimo, no facilitan el cumplimiento de las medidas ni el seguimiento por parte de los 
profesionales. Cierto es que los barrios más céntricos, debido a las mayores y mejores posibilidades de acceso a la red pública de transportes urbanos (metro, autobús y tranvía) se encuentran en mejor posición, más equitativa, con respecto a otros barrios situados en la periferia norte y sur. Sin embargo, la adjudicación del centro de internamiento no siempre está sujeta a la cercanía al usuario, sino, en habitualmente, a las posibilidades de oferta del servicio o al número de plazas libres. En la mayoría de los casos, pues, la distancia se incrementa respecto a lo previsible.

Hay que tener en cuenta también el número de plazas, con el que no hemos contado hasta ahora. En total, en el área metropolitana se localizan 227 plazas en centros de Reeducación, de las que sólo 25 se localizan en la ciudad y en un barrio que presenta un índice de incidencia de la delincuencia adolescente medio. Se trata de un número de plazas claramente insuficiente compensado por otros centros localizados en Castellón y Alicante, a todas luces excesivamente alejados del entorno de los jóvenes. La escasez de plazas próximas en el medio cerrado, conlleva que un ACL no sea ingresado en el centro más próximo, sino en el que hay plaza, impidiendo el proceso de intervención socio educativa de proximidad (véase tabla 4 en el anexo).

Por último, cabe señalar el caso del Centro de Medidas Judiciales de Medio Abierto, un centro único y que, como veremos, debe dar servicio a toda la ciudad de Valencia. La distancia, en este caso, es una barrera importante, tanto para el usuario como para el profesional que, en ocasiones realiza el servicio en el entorno del adolescente. La distancia junto al aumento en la ratio de ACL de los educadores y trabajadores sociales impide lógicamente dedicar el tiempo necesario para acompañar en el proceso y facilitar su integración en los programas y recursos del territorio que son los que pueden garantizar a medio plazo el abandono de las conductas delictivas.

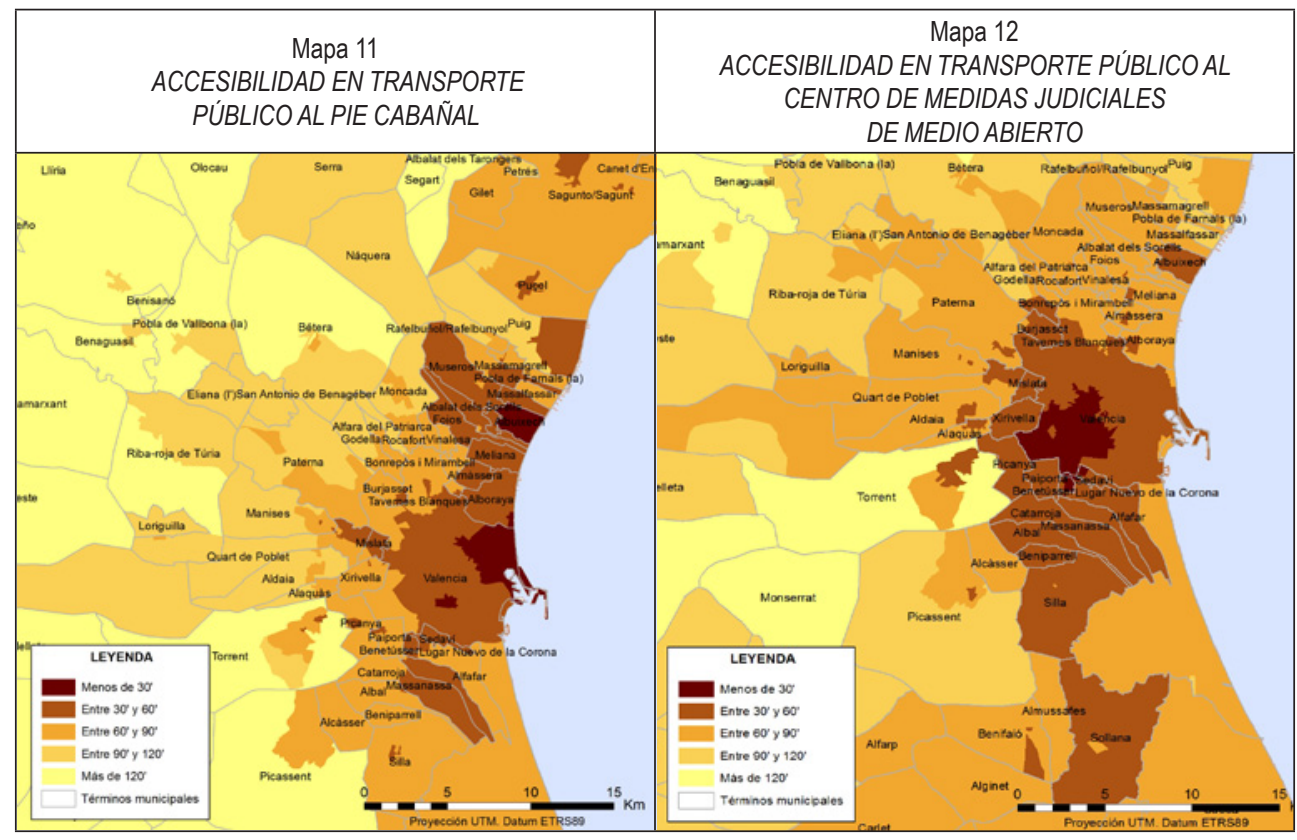

Fuente: Elaboración propia. 


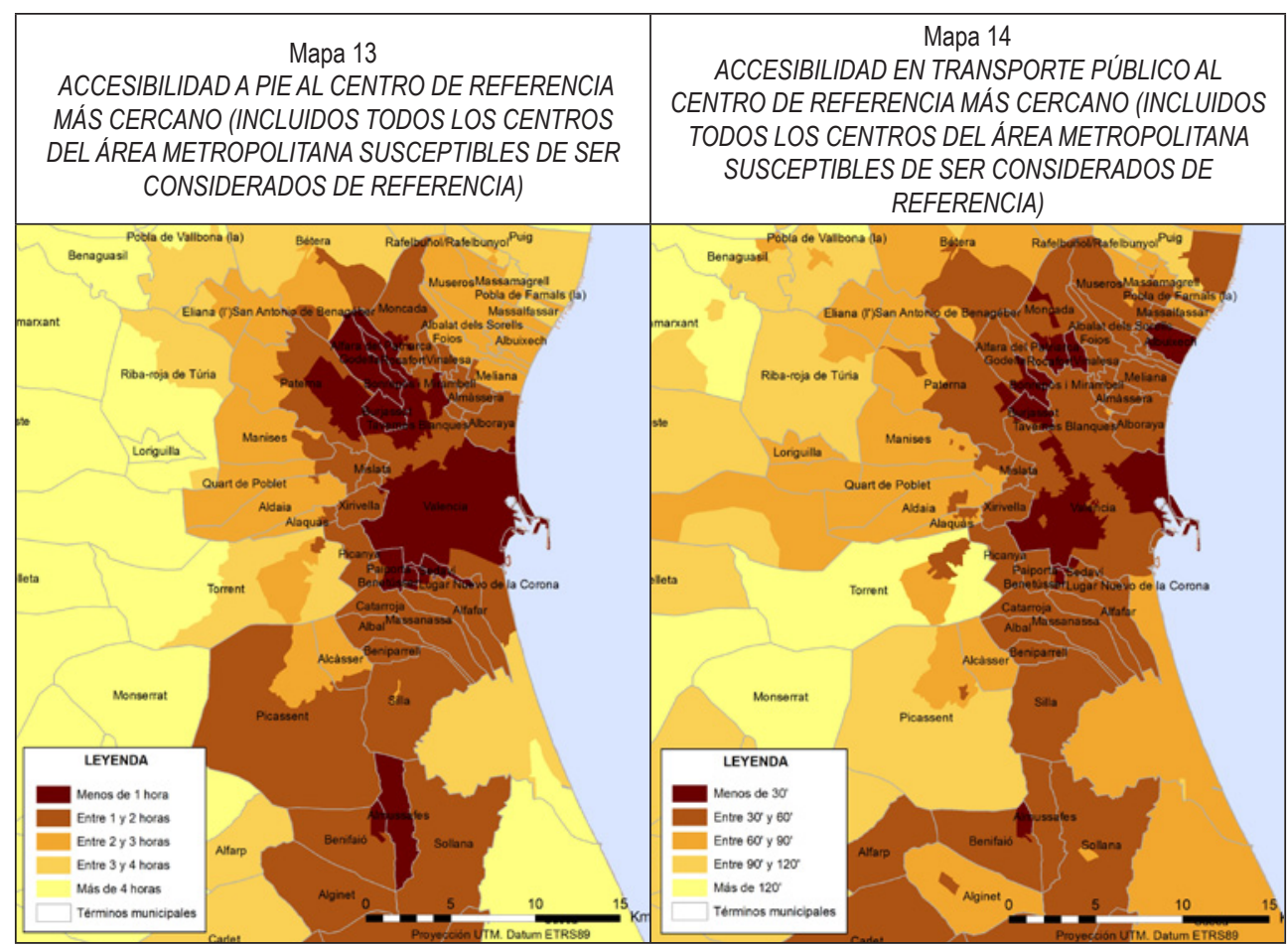

Fuente: Elaboración propia.

\section{IV.2.2. La vinculación entre accesibilidad e intervención. La percepción de los expertos}

A partir de entrevistas a informadores cualificados, todos ellos profesionales vinculados a las medidas de intervención con jóvenes y adolescentes, podemos completar la información cuantitativa hasta ahora reflejada. Cabe comenzar por la preocupación que todos los informantes señalan por la estructura de atención a los ACL de la ciudad de Valencia. La dependencia orgánica y funcional de diferentes administraciones, la ubicación en el territorio del programa de ejecución de medio abierto y de los centros, la ratios de atención -muy altas-, etc., lo que conlleva la ausencia de proximidad física y dificulta el desarrollo de intervenciones eficaces.

En cuanto al Centro de medidas judiciales de medio abierto, por el cual han de pasar todos los ACL, ya tengan medida de medio abierto o de internamiento en centro (cerrada, semiabierta o abierta), ya que todos los jóvenes sujetos a una medida de internamiento han de cumplir, a la finalización de la misma, un periodo de libertad vigilada tal como refleja el artículo $7.2^{13}$ de la LORPM 5/2000, cabe señalar que la oferta es considerada por los entre-

13 El artículo 7.2 de la Ley señala lo siguiente: «Las medidas de internamiento constarán de dos períodos: el primero se llevará a cabo en el centro correspondiente, conforme a la descripción efectuada en el apartado anterior de este artículo, el segundo se llevará a cabo en régimen de libertad vigilada, en la modalidad elegida por el Juez.». 
vistados como especialmente problemática, en particular por su ubicación física, pues, como hemos visto, se encuentra en un barrio ubicado en uno de los extremos de la ciudad:

«Estamos aquí, ya ves lejos, es difícil realizar intervenciones próximas, porque el equipo está lejos de muchos chavales (...) si te desplazas tú, con una visita entre que llegas, te haces con el chaval se te puede ir casi toda la mañana, y no estamos para eso» (Informador-3).

«Y sobre todo estamos lejos de los barrios con más ACL, y de esos que tienen muchos delitos, para ellos sería necesario una intervención de más intensidad y proximidad (...), a estos los pierdes y acaban en la cárcel» (Informador -2).

«No se ha fomentado el medio abierto; el medio cerrado va aumentando en profesionales, plazas, etc. y el medio abierto no, cada vez la ratio por educador y ACL es mayor» (Informador -1)

«Al inicio se estuvo con un ratio de $12-13$, ahora con $28-30$, y sería adecuado no más de 15 (...). Yo creo que el chip viene de la justicia de adultos, basada en el castigo más que en la reinserción de la gente, para ésta hay que estar cerca, tener tiempo y recursos (...)» (Informador -4$)$.

Los ACL, en función de su vulnerabilidad precisan de una intervención más intensiva, y próxima, a su vez los educadores y trabajadores sociales necesitan acompañar al adolescente en su proceso de inserción social para aumentar sus oportunidades vitales, su formación, etc., que posibiliten el abandono de la actividad delictiva. En este sentido, el medio abierto precisa de la colaboración del resto de instituciones de la comunidad para la elaboración y seguimiento del itinerario de intervención del adolescente (la escuela, los recursos de inserción laboral, las unidades de conductas adictivas, los servicios sociales de zona, etc.):

«Pues les buscamos la EPA ${ }^{14}$, escuelas-taller ${ }^{15}$, TFIL's, lo que pueda ser para que igual con esa pequeña formación pueda entrar en el mundo laboral, estrujar las redes familiares (...), si el chaval tiene un problema de salud mental y no está diagnosticado, eso es lo habitual, si tiene un problema de consumo que vaya a la $\mathrm{UCA}^{16}$, le seguimos, le acompañamos, pero para eso necesitamos estar cerca sino los perdemos, pues desde la distancia con estos chavales no se consigue nada, y con los más tocaos que no puedes contar con la familia, necesitas estar a mano». (Informador -1).

Los centros de internamiento disponen de una larga trayectoria en el sistema, con diferentes denominaciones, pues han formado parte del mismo en sus diferentes épocas. Es lo más consolidado del sistema, ya que durante décadas se consideró que el tratamiento del delincuente había de ser lejos de su comunidad (igual que el enfermo mental) (Uceda, 2011).

14 Escuela Permanente de Adultos.

15 Escuelas-Taller y Casas de Oficios, Talleres de Empleo, Talleres de Formación e Inserción Laboral son acciones de formación e inserción laboral promovidas por la Generalitat Valenciana para diferentes colectivos de desempleados/as. Para conocer sus características, metodología de funcionamiento, etc.

16 Unidad de Conductas Adictivas dependientes de la Conselleria de Sanitat de la Generalitat Valenciana. 
Los nuevos postulados señalan que es precisamente en la comunidad donde hay que trabajar, para prevenir y para insertar, pues el adolescente o joven siempre volverá a su lugar de residencia, a su barrio o municipio:

«Los niños y los adolescentes entran en el centro de menores que depende de la Generalitat, no hay ninguna relación con la red de recursos sociales de base (...) entre otras cosas porque estamos lejos unos de otros, los centros del equipo de medio abierto, el equipo de medio abierto de los barrios, los centros de los barrios, etc.; la proximidad brilla por su ausencia». (Informador -4).

«Estos otros chicos, la cosa se va enquistando si no los sacas de ese entorno. Y a veces si los sacas y los internas y salen..., pero el problema es que en los centros evolucionan favorablemente, y cuando salen vuelven al mismo sitio. Y ese es el trasfondo, que vuelven al sitio y no hay servicios de zona para trabajar con ellos» (Informador -2).

«Si el entorno ha hecho que cometa delitos y sigue en el mismo entorno y no se ha trabajado en el entorno, tiene todas las papeletas para que en dos meses vuelva. Si reincide pienso que es un conjunto de todo, ¿quién está en el entorno?» (Informador -3 ).

Los resultados cualitativos muestran una gran complejidad de factores que intervienen, pero en todos aparece con fuerza inusitada las palabras entorno, proximidad, comunidad, recursos en el barrio o distrito, trabajo en red, cuestiones todas vinculadas al territorio que están coadyuvando en el fracaso de las políticas de actuación con los ACL. Es preciso trabajar en el entorno desde la prevención pero también para la reinserción, pues los centros constituyen espacios artificiales de convivencia y cumplimiento de medidas, pero sin el entorno, sin el barrio, no pueden trabajar la inserción o reinserción de los ACL en su comunidad (en su territorio), que es sin duda aquello que hará que abandonen la actividad delictiva.

\section{CONCLUSIONES}

En este artículo hemos realizado una aproximación al territorio, a la exclusión social residencial, a la delincuencia juvenil y a las políticas públicas de intervención con los ACL, donde el territorio cobra especial relevancia. Se abren nuevas e interesantes posibilidades en el análisis territorial de la exclusión social a partir del uso de SIG y con una visión multidisciplinar en la que los geógrafos podemos aportar un interesante punto de vista que complementa otros enfoques científicos en particular desde otras ciencias sociales como el Trabajo Social o las ciencias políticas.

El efecto barrio existe. Es evidente que el barrio donde un adolescente reside es importante para su desarrollo como joven y como adulto, ya que es en el mismo donde pasa gran parte de su tiempo, donde reside su familia, acude a la escuela, se socializa con sus iguales y encuentra sus referentes más inmediatos.

La influencia del territorio es persistente en el tiempo si no se realizan las intervenciones públicas adecuadas, bien de la mano del urbanismo o bien de la de la oferta de servicios y equipamientos. Existe una asociación entre barrios desfavorecidos y concentración de delin- 
cuencia juvenil, que puede romperse con medidas más allá de las puramente judiciales o punitivas. La intervención social en el territorio, en el barrio, la cercanía y la oferta de oportunidades son una de las claves para la mejora del entorno y la reducción de la delincuencia juvenil.

Parece claro que el fenómeno urbano (construcción, distribución de la población, accesibilidad a la vivienda, equipamientos, etc.) influye en la vulnerabilidad y exclusión social y en consecuencia, en el desarrollo de las trayectorias delictivas, aunque no es, evidentemente, el factor fundamental. Las diferencias en el acceso a la vivienda suponen la distribución de la población según su capacidad económica, lo que genera una segregación urbana y social difícil de solventar. Cabe recordar que en la ciudad de Valencia el boom inmobiliario de los 90 y primera década del presente siglo, ha supuesto una cierta transformación urbana a partir del filtrado de población (huida de la población a mejores viviendas y barrios y llegada de nueva población con menores capacidades, reorganización del mercado inmobiliario), y la consolidación de barrios marginales, por no haber sido escogidos para la nuevas operaciones urbanísticas, como es el caso de Poblats Marítims, Russafa, Orriols, Torrefiel, Benicalap, Tendetes, L'Olivereta y Quatre Carreres (Sorribes y Pedro, 2004), que coinciden con los distritos históricos o emergentes de mayor concentración de ACL.

La relación entre la localización de las estructuras de intervención con los ACL (ya sea de medio abierto o cerrado) y la localización de la residencia de los mismos, es básica para conseguir una adecuada reinserción del joven, ya que se parte de la premisa que la trayectoria de los ACL se realiza en un territorio (barrio), que a su vez es el espacio social de la intervención profesional. Desde esta perspectiva, la escasa capacidad de respuesta de los Centros de Medio Abierto y de los Centros de Reeducación en la gestión de la prevención e intervención social se debe a múltiples situaciones que podríamos sintetizar en las siguientes: a) dificultad para intervenir desde una perspectiva territorial; b) aumentos desproporcionados en la ratio ACL/profesional; c) nula relación entre los centros y los recursos (sociales y comunitarios) ubicados en el territorio y d) dificultad de acceso (por excesiva distancia) entre el servicio municipal y el usuario.

Obviar que los ACL son personas sociales y relacionales, que forman parte de dinámicas contextuales y que son atrapados por ellas o transformados con ellas, únicamente puede abocar a un itinerario de fracaso colectivo en la intervención. El territorio es el espacio natural de la socialización, de la interacción y, en síntesis, el lugar del cambio, de la transformación y de las sinergias, por lo que es necesario su planificación, generando dinámicas de prevención, de ocupación del tiempo libre, de formación e inserción laboral, en general, de desarrollo comunitario para favorecer una actitud positiva en los adolescentes y en el conjunto de residentes, ya que como dice (Morente et al., 2008) «es fundamental para el desarrollo moral y la adquisición de una identidad equilibrada y justa de los jóvenes, la inserción en una comunidad basada en la democracia participativa» (p.231).

\section{REFERENCIAS}

ALLARD, S.W. (2004): «Access to social services: the changing urban geography of poverty and service provision», Metropolitan Policy Program, The Brookings Institution, Survey Series, 1-19. 
ARIAS, F. (Dir.) (2000): La desigualdad urbana en España, Madrid, Ministerio de Fomento, en http://habitat.aq.upm.es/due/ (consultado: 5-6-2013).

ATKINSON, R. y KINTREA, K. (2001): «Disentangling Area Effects: Evidence from deprived and non-deprived neighbourhood Effects and Cultural Exclusion». Urban Studies, 39, 85-93.

AZAGRA, J. y ROMERO, J. (2007): Pais complex. València, Servei de Publicacions de la Universitat de València.

BHAT, CH., et al. (2000): Development of an Urban Accessibility Index: Literature Review, Centre of Transportation Research, Austin, The University of Texas.

BOURDIEU, P. (1999): La miseria del mundo. Madrid, Akal.

BROOKS-GUNN, J. DUCAN, G.J., KLEBANOV, P.K. y SEALAND, N. (1993): «Do neighbourhoods affect child and adolescent development?». American Journal Sociology, 99, 353-395.

CABRALES, L. y CANOSA, E. (2003): «Gestionar la exclusión: el desarrollo de fraccionamientos cerrados de lujo en la ciudad de Guadalajara», en MANERO, F. y PASTOR, L. (orgs.). El espacio latinoamericano. Cambio económico y gestión urbana en la era de la globalización. Valladolid: Editorial de la Universidad de Valladolid, 555-564.

CAPARROS, P. (2001): «Fragmentació social a les ciutats. Apunts per a l'estudi de la dualitat a les nostres ciutats», Revista Catalana de Sociología, 14, 277-285.

CASTEL, R. (1997): La metamorfosis de la cuestión social. Una crónica del asalariado. Barcelona, Paidós.

CASTELLS, M. (1995): La ciudad informacional, tecnologías de la información, reestructuración económica y el proceso urbano-regional, Alianza Ed., Madrid.

CEBOLLADA, A. (2006): "Aproximación a los procesos de exclusión social a partir de la relación entre el territorio y la movilidad cotidiana», Documents d'Anàlisi Geogràfica, 48, 105-121.

DAVOUIDI, S., et al. (2009): «El desarrollo territorial: entre la perspectiva ambiental, la cohesión social y el crecimiento económico», Feria, J.M., et al (eds.) Territorios, Sociedades y Políticas, Sevilla, Universidad Pablo de Olavide y AGE.

FRAILE, P. (2007): «La percepción de seguridad: entre el delito, el conflicto y la organización del espacio». Scripta Nova. Revista Electrónica de Geografía y Ciencias Sociales. Barcelona: Universidad de Barcelona, 1 de agosto de 2007, vol. XI, núm. 245 (62). <http://www.ub.es/geocrit/sn/sn-24562.htm> [ISSN: 1138-9788]

FRAILE, P. y BONASTRA, Q. (2011): «Espacio, delincuencia y seguridad: hacia el diseño de un modelo de anàlisis territorial», en Boletín de la Asociación de Geógrafos Españoles, $\mathrm{n}^{\circ}$ 57, 123-146.

GARROCHO, C. y CAMPOS, J. (2006): «Un indicador de accesibilidad a unidades de servicios clave para ciudades mexicanas: fundamentos, diseño y aplicación», Economía, Sociedad y Territorio, vol. VI, n. 22, 1-60.

GONZÁLEZ-TASCON, M.M. (2010): El tratamiento de la delincuencia juvenil en la Unión Europea. Hacia una futura política común, Valladolid, Lex Nova.

HARVEY, D. (1976): «Geografía y Teoría revolucionaria», Geo-Crítica, Barcelona, Vol. 1, $\mathrm{n}^{\circ}$ 4, en http://www.ub.edu/geocrit/geo4.htm (consultado: 1-05-2013).

HARVEY, D. (1977): Urbanismo y desigualdad social, Madrid, Siglo XXI.

HARVEY, D. (2003): Espacios de esperanza. Madrid: Akal. 
HERBERT, D.T. (1982): Geography of Urban Crime, New York, Longman.

HERNANDO, F. (2006): «Eclecticismo y diversidad en la Geografía del crimen y la delincuencia en el cambio de siglo», Anales de Geografía, 26, 9-30.

HERIN, R. (2008): «Violencias en las periferias urbanas francesas. Los disturbios del otoño de 2005», Scripta Nova. Revista Electrónica de Geografía y Ciencias Sociales, 270, 96, Barcelona: Universidad de Barcelona, 1 de agosto de 2008, vol. XII, núm. 270 (96). <http://www.ub.es/geocrit/sn/sn-270/sn-270-96.htm> (consultado: 10 -05-2013)

JENKS, C. y MAYER, S.E. (1990): «The social consequences of growing up in a poor neighbourhood»; en MC GEARY, M. (Ed,) Inner-city poverty in the United States. Washington, Nacional Academy Press.

LAHOSA, J.M. (2002): «Delincuencia y ciudad. Hacia una reflexión geográfica comprometida». Biblio 3W, Revista Bibliográfica de Geografía y Ciencias Sociales, Universidad de Barcelona, Vol. VII, n 349, 20 de febrero de 2002. http://www.ub.es/geocrit/b3w-349.htm [ISSN 1138-9796]

MARTIN, R. (2001): «Geography and public policy: the case of the missing agenda», Progress in Human Geography, 25, 2, 189-210.

MASSEY, D. (2004): «Lugar, identidad y geografías de la responsabilidad en un mundo en proceso de globalización», Treballs de la Societat Catalana de Geografia, 57, 77-84.

MAY, J. y THRIFT, N.J. (Eds.) (2001): Timespaces. Geographies of temporality. London. Roudledge.

MIRALLES, C. (2002): Transporte y ciudad. El binomio imperfecto. Barcelona: Ariel.

MIRALLES, C. (2011): «Dinámicas metropolitanes y tiempos de la movilidad. La región metropolitana de Barcelona, como ejemplo», Anales de Geografia, vol. 31, n. 1, pp. 125-145.

MONTERO, T. (2007): «La delincuencia juvenil en España en datos», Derecho y cambio social, en http://www.derechoycambiosocial.com/revista023/Delicuencia_juvenil.pdf (consultado: 01-06-2013)

MORENTE, F. et al. (2008): El laberinto social de la delincuencia. Jóvenes adolescentes en la encrucijada. Madrid. Dykinson, S.L.

MÜCKENBERG, H. (2009): Familia, política del temps i deservolupament urbà. L'Exemple de Bremen, Barcelona. IERMB.

MUSTERD, S.; MURIE, A. y KESTELOOT, C. (Eds.). (2006): Neighbourhoods of poverty: Urban social exclusion and integration in Europe. Londres, Palgrave.

PAIN, R. (2003): «Social Geography: on action-oriented research», Progress inHuman Geography, 27, 5, 649-657.

PARK, R.E. y BURGUESS, E. (Coord.) (1984) [1925]: The city, Chicago, Chicago University Press.

PATTON, M.Q. (1990): «Qualitative Evaluation and Research Methods», London. Sage.

PAUGAM, S. (2007): Las formas elementales de la pobreza. Madrid, Alianza editorial.

PEDRO, A, y SORRIBES, J. (2004): «El boom inmobiliari al Pais Valencia», L'Espill, 16, 60-69.

PICO, J. y SERRA, I. (2010): La Escuela de Chicago de Sociología, Madrid. Ed. Siglo XXI. 
PORCELL, S. et al. (2011): Habitus i Hàbitat: La incidència de la segregació urbana entre la població jove de la Regió Metropolitana de Barcelona, Bellaterra, Institut d'Estudis Regionals i Metropolitans de Barcelona.

REDONDO, S.; MARTÍNEZ, A y ANDRES, A (2011): Factores de éxito asociados a los programes de intervención con menores infractores, Serie Informes, Estudios e Investigación, Madrid, Ministerio de Sanidad, Política Social e Igualdad.

SÁEZ, J., PINAZO, S. y SÁNCHEZ, M. (2008): «La construcción de los conceptos y su uso en las políticas sociales orientadas a la vejez: la noción de exclusión y vulnerabilidad en el marco del envejecimiento». Trabajo e inmigración, 75, Madrid. Ministerio de Trabajo e Inmigración, 75-94.

SMITH, N. (1996): The new urban frontier: gentrification and the revanchist city, Londres, Routhledge.

SOJA, E. (1996): Thirdplace. Journey to Los Angeles, Blackwell, USA.

SORRIBES, J. y PEDRO, A. (2004): «El boom inmobiliari al País Valencià», en L'Espill, 16, 60-69.

SUBIRATS, J. (Dir.) (2005): Análisis de los factores de exclusión social, Fundación BBVA Disponible en: http://www.fbbva.es/TLFU/dat/exclusion_social.pdf

SUBIRATS, J. et al. (2008): Análisis y Gestión de Políticas públicas, Barcelona, Ariel.

UCEDA, F. X. (2011): Adolescentes en conflicto con la ley. Una aproximación comunitaria: Trayectorias, escenarios e itinerarios. Tesis Doctoral. València. Universitat de València.

URTEAGA, E. (2012): «Segregación y estigmatización de los barrios desfavorecidos en Francia», Biblid, XII-1, 39-47.

VALLÉS, M.S. (1999).Técnicas Cualitativas de Investigación Social. Reflexión Metodológica y Práctica Profesional. Madrid, Síntesis Sociológica.

VEIGA, D. (2000): «Notas para una agenda de investigación sobre procesos emergentes en la sociedad urbana», en TORRES RIVERO (ed.) Repensando la experiencia urbana de América Latina: cuestiones, conceptos y valores, Buenos Aires: CLACSO.

VEIGA, D. (2009): «Desigualdades sociales y fragmentación urbana», en POGGIESE, H. y COHEN, T. (Ed.). Otro desarrollo urbano: ciudad incluyente, justicia social y gestión democrática, Buenos Aires, CLACSO, 51-62.

WACQUANT, L.J. (2007): Los condenados de la ciudad. Gueto, periferias y Estado. Madrid, Siglo XXI.

WACQUANT, L.J. (2008): Urban outcasts: a comparative sociology of advanced marginality. Cambridge, Polity.

WILSON, J. (1987): The Truly Disadvantaged. The Inner City, the underclass, and Public Policy. Illinois, University of Chicago Press.

WIRTH, L. (1927): «The gueto», The American Journal of Sociology, 33, 1, p. 57-71.

ZARZURI, R. (2000): «Notas para una aproximación teórica a las nuevas culturas juveniles: las tribus urbanas». Revista Última Década, 13, 81-96. 


\section{ANEXO \\ FICHA TÉCNICA DE LA ENCUESTA. N=1.200.2012.}

UNIVERSO: Infinito, ya que consideramos toda la población del Área Metropolitana de Valencia estamos en $\mathrm{N}=1.830 .774$ habitantes distribuidos en 75 municipios.

MUESTRA: Entre 1.111 y 1.411 encuestados, en función de la varianza poblacional que consideramos p y q iguales a 50\%. Un nivel de confianza de 95,5\%, es decir, de 2 sigmas. Y un error muestral no superior $\mathrm{a} \pm 2,5$

TIPO DE MUESTREO: consideramos que el muestreo polietápico es idóneo. Inicialmente un muestreo no probabilístico con asignación de un perfil previo de tipo de municipio. Y en una segunda fase, elaboramos unos estratos proporcionales a su peso estadístico, en función de dos variables: grupos de edad y género, con selección aleatoria en centros sociales.

\section{AFIJACIÓN DE LA MUESTRA:}

\begin{tabular}{|l|c|c|c|c|c|c|}
\hline \multirow{2}{*}{ TIPO DE MUNICIPIO } & POBLACIÓN & \multicolumn{4}{|c|}{ NÚMERO DE ENTREVISTAS } & \multirow{2}{*}{ Totales } \\
\cline { 3 - 6 } & TOTAL & $18-24$ & $25-44$ & $45-65$ & +65 & \\
\hline Hasta 2000 habitantes & $5 \%$ & 10 & 17 & 19 & 10 & 56 \\
\hline De 2001 a 10000 habitantes & $18 \%$ & 36 & 62 & 68 & 34 & 200 \\
\hline 10001 a 50000 habitantes & $33 \%$ & 66 & 114 & 125 & 62 & 367 \\
\hline+ 50000 habitantes & $44 \%$ & 88 & 152 & 166 & 83 & 489 \\
\hline TOTAL & $100 \%$ & 200 & 345 & 378 & 189 & 1.112 \\
\hline
\end{tabular}

Tabla 4

CENTROS, TITULARIDAD, TIPOLOGÍA Y NÚMERO DE PLAZAS

DE LA OFERTA EN EL ÁREA METROPOLITANA DE VALENCIA

\begin{tabular}{|l|l|c|l|}
\hline Centro & Titularidad y gestión & Plazas & Régimen y ámbito personal \\
\hline $\begin{array}{l}\text { Centro de Reeducación } \\
\text { «Colonia San Vicente Ferrer». } \\
\text { Burjassot. Valencia }\end{array}$ & $\begin{array}{l}\text { Generalitat Valenciana } \\
\text { y gestión mixta del } \\
\text { centro }\end{array}$ & 72 & $\begin{array}{l}\text { Medidas cautelares y firmes en los regíme- } \\
\text { nes abiertos y semiabiertos de 14-18 años, } \\
\text { y en régimen cerrado de 14-16 años }\end{array}$ \\
\hline $\begin{array}{l}\text { Centro de Reeducación «Pi i Margall». } \\
\text { Burjassot. Valencia }\end{array}$ & $\begin{array}{l}\text { Generalitat Valenciana } \\
\text { gestión privada }\end{array}$ & $\begin{array}{l}\text { Internamientos terapéuticos de salud mental } \\
\text { (preferentemente). Medidas cautelares y fir- } \\
\text { mes en regímenes semiabiertos y cerrados, y } \\
\text { en todas las edades }\end{array}$ \\
\hline $\begin{array}{l}\text { Centro de Reeducación «Mariano Ribera». } \\
\text { Burjassot. Valencia }\end{array}$ & $\begin{array}{l}\text { Generalitat Valenciana } \\
\text { y gestión privada }\end{array}$ & 60 & $\begin{array}{l}\text { Medidas cautelares y firmes en todos los } \\
\text { regímenes y edades. }\end{array}$ \\
\hline $\begin{array}{l}\text { Centro de Reeducación «Jaume I». } \\
\text { Picassent. Valencia }\end{array}$ & $\begin{array}{l}\text { Titularidad y gestión } \\
\text { privadas. }\end{array}$ & $\begin{array}{l}\text { Medidas cautelares y firmes en todos los } \\
\text { regímenes y edades. }\end{array}$ \\
\hline $\begin{array}{l}\text { Centro de Reeducación El Cabanyal } \\
\text { (Valencia) }\end{array}$ & $\begin{array}{l}\text { Titularidad y gestión } \\
\text { pública. }\end{array}$ & $\begin{array}{l}\text { Medidas cautelares y firmes en todos los } \\
\text { regímenes de 14 y 15 años. }\end{array}$ \\
\hline $\begin{array}{l}\text { Equipo de Medidas Judiciales de Medio } \\
\text { Abierto de Valencia. Valencia. }\end{array}$ & $\begin{array}{l}\text { Titularidad pública y } \\
\text { gestión mixta }\end{array}$ & - & - \\
\hline
\end{tabular}

Fuente: Elaboración propia a partir de Uceda (2011). 